NBER WORKING PAPER SERIES

\title{
GOVERNMENT FINANCE IN THE WAKE OF CURRENCY CRISES
}

\author{
Craig Burnside \\ Martin Eichenbaum \\ Sergio Rebelo \\ Working Paper 9786 \\ http://www.nber.org/papers/w9786
}

\section{NATIONAL BUREAU OF ECONOMIC RESEARCH 1050 Massachusetts Avenue Cambridge, MA 02138}

June 2003

\begin{abstract}
We are grateful for an NSF grant through the National Bureau of Economic Research and a grant from the World Bank. The opinions in this paper are those of the authors and not necessarily those of the Federal Reserve Bank of Chicago or the World Bank. We thank Martin Bodenstein, Yuliya Mescheryakova and Jeffrey Wood for valuable comments and Selim Elekdag, Su Youne Lee and Mi Hwa Park for invaluable assistance with data. The views expressed herein are those of the authors and not necessarily those of the National Bureau of Economic Research.

(C)2003 by Craig Burnside, Martin Eichenbaum, and Sergio Rebelo. All rights reserved. Short sections of text not to exceed two paragraphs, may be quoted without explicit permission provided that full credit including (C) notice, is given to the source.
\end{abstract}


Government Finance in the Wake of Currency Crises

Craig Burnside, Martin Eichenbaum, and Sergio Rebelo

NBER Working Paper No. 9786

June 2003

JEL No. F31

\section{$\underline{\text { ABSTRACT }}$}

This paper addresses two questions: (i) how do governments actually pay for the fiscal costs associated with currency crises; and (ii) what are the implications of different financing methods for post-crisis rates of inflation and depreciation? We study these questions using a general equilibrium model in which a currency crisis is triggered by prospective government deficits. We then use our model in conjunction with fiscal data to interpret government financing in the wake of three recent currency crises: Korea (1997), Mexico (1994) and Turkey (2001).

\section{Craig Burnside}

Department of Economics

University of Virginia

114 Rouss Hall

P.O. Box 400182

Charlottesville, VA 22904-4182

Martin Eichenbaum

Department of Economics

Northwestern University

Evanston, IL. 60208

Sergio Rebelo

Kellogg School of Management

Leverone Hall

Northwestern University

Evanston, IL 60208-2001 


\section{Introduction}

A classical view of currency crises is that they arise because governments print money to finance ongoing or prospective deficits. ${ }^{1}$ Models embodying this view generally predict that seigniorage should rise significantly in the aftermath of a currency crisis. Table 1, which reports data for six recent currency crises, indicates that this prediction is inconsistent with the data. This evidence raises two questions:

- How do governments actually pay for the fiscal costs associated with currency crises?

- What are the implications of different financing methods for post-crisis rates of inflation and depreciation?

We address these questions using a general equilibrium model in which a currency crisis is triggered by prospective government deficits. ${ }^{2}$ We then use our model in conjunction with fiscal data to interpret government financing in the wake of three recent currency crises: Korea (1997), Mexico (1994), and Turkey (2001).

Generating empirically plausible answers to our two questions requires that we adopt a formulation of the government's budget constraint that is more realistic than the highly stylized representations typically used in the literature. Standard models assume, for convenience, that the only source of depreciation-related revenue available to a government is seigniorage. In reality governments have access to other types of depreciation-related revenue. First, they can deflate the dollar value of outstanding nonindexed debt. ${ }^{3}$ Second, they can engage in what we call an 'implicit fiscal reform'. Such a reform arises when some government expenditures are denominated in units of the local currency. As long as the government does not raise these expenditures at the rate of depreciation their dollar value declines. This 'implicit fiscal reform' can be quantitatively important even if government

\footnotetext{
${ }^{1}$ See, for example, Krugman (1979), Flood and Garber (1984), Obstfeld (1986), Calvo (1987), Drazen and Helpman (1987), Wijnbergen (1991), Corsetti, Pesenti and Roubini (1999), Burnside, Eichenbaum and Rebelo (2001), and Lahiri and Végh (2003).

${ }^{2}$ Burnside, Eichenbaum and Rebelo (2003) provides a preliminary discussion of these questions using a simple reduced form model featuring a Cagan (1956) money demand function, a simplified government budget constraint, and preliminary data from Korea and Mexico.

${ }^{3}$ The importance of nonindexed debt has been emphasized in the literature on the fiscal theory of the price level. Sims (1994), Woodford (1995) and Cochrane (2001) discuss the fiscal theory in a closed economy context. Dupor (2000), Daniel (2001), and Corsetti and Mackowiak (2002) analyze the implications of the fiscal theory for open economies.
} 
expenditures rise at the same rate as domestic inflation. This is because post-crisis inflation rates are often much lower than the rate of depreciation (see Table 2).

Our empirical analysis indicates that debt deflation and implicit fiscal reforms are more important than seigniorage, at least in the first few years after a crisis. Our theoretical analysis shows that, once these sources of revenue are incorporated into the model, we can account for government financing in a way that is consistent with post-crisis rates of inflation and depreciation.

We consider a standard small open economy model populated by a representative, infinitely lived agent who can borrow and lend at a fixed interest rate in world capital markets. Agents in the economy consume tradable and nontradable goods and receive endowments of both goods. In addition to allowing for nonindexed public debt and government spending, we assume that some government spending is on nontradable goods. This is important because in reality the dollar price of nontradable goods falls dramatically in the aftermath of a currency crisis (see Table 3). This fall has two effects on the government's intertemporal budget constraint. First, it lowers the dollar value of taxes collected from the nontradable sector. This effect underlies the conventional wisdom that a devaluation leads to a deterioration of the government's fiscal position. ${ }^{4}$ Second, the fall in the dollar price of nontradables reduces the dollar value of government expenditures on nontradable goods. This second effect, which has not been stressed in the literature, leads to an improvement of the government's fiscal position. Since most governments' expenditures are on nontradable goods (e.g. health and education), the latter effect may, in practice, be very important.

Consistent with the data, we also assume that nontradable prices are sticky for a brief period of time. In addition, we suppose that distributing tradable goods requires the use of nontradable distribution services (retailing, wholesaling, and transportation). Given these assumptions, the model implies that the rate of depreciation in the first year after the crisis is larger than the rate of inflation. The presence of this wedge magnifies the post-crisis reduction in the dollar value of transfers and government purchases. This decline goes a long way toward offsetting the fall in the dollar value of taxes.

We show that a version of our model calibrated to Korean data is consistent with the postcrisis behavior of inflation and depreciation rates in Korea. In terms of government finance, seigniorage accounts for less than 15 percent of the fiscal costs associated with the crisis.

\footnotetext{
${ }^{4}$ This deterioration may be less severe in countries where taxes on commodity exports are an important source of revenue. See Pinto (1990), Easterly and Schmidt-Hebbel (1994), and Morris (1995) for a discussion.
} 
The balance is paid for through a reduction in the dollar value of transfer payments and, to a lesser extent, debt deflation. The model implies that if all debt and transfer payments had been indexed to the dollar, Korea's post-crisis inflation would have been dramatically different. Specifically, in the first year of the crisis inflation would have been more than twice as high, while long run inflation would have risen by a factor a ten.

The central feature of our model is that governments have at their disposal a menu of depreciation-related revenues. To assess the importance of these alternative revenue sources we conduct detailed case studies of how Korea, Mexico and Turkey financed the costs associated with their recent currency and banking crises. ${ }^{5}$ In practice this is a difficult task because one must compare actual revenues and expenditures with what they would have been absent the crisis. While our precise quantitative results are sensitive to these assumptions, we have confidence in the basic qualitative patterns that emerge. These can be summarized as follows. First, none of these countries has fully paid for all of the costs associated with their currency crisis. Second, in no case has seigniorage been the dominant source of revenue. Third, for all three countries, debt deflation has been more important than seigniorage. Fourth, consistent with conventional wisdom, there was a substantial decline in the dollar value of tax revenues after the crisis in all three countries. However, the decline in the dollar value of government purchases was important in offsetting the tax revenue decline. Finally, there were large declines in the dollar value of transfers. Indeed, these declines were the single most important source of revenue in Korea and Mexico.

The remainder of the paper is organized as follows. Section 2 discusses the government budget constraint. Section 3 embeds this budget constraint into a general equilibrium model of a currency crisis. Section 4 presents the properties of the model. In section 5 we summarize the results of our case studies. Finally, section 6 contains concluding remarks.

\section{The Government Budget Constraint}

Explicit default aside, a government must satisfy its lifetime budget constraint. In this section, we derive a version of this constraint that is useful for discussing the different strategies that a government can use to pay for the fiscal costs associated with a currency crisis. This requires distinguishing between traded and nontraded goods. Since the prices of

\footnotetext{
${ }^{5}$ See Persson, Persson and Svensson (1998) for a careful analysis of the effects of inflation on the budget constraint of the Swedish government that considers inflation-related sources of revenue other than seigniorage.
} 
these goods play an important role in our analysis, we begin by laying out our notation and assumptions about purchasing power parity (PPP).

Purchasing Power Parity Burstein, Eichenbaum, and Rebelo (2002) argue that for large devaluations PPP is a reasonable assumption for the producer price of tradable goods. In light of this we assume that:

$$
\bar{P}_{t}^{T}=S_{t} \bar{P}_{t}^{T *}
$$

Here $\bar{P}_{t}^{T}$ and $\bar{P}_{t}^{T *}$ denote the domestic and foreign producer price of tradable goods, respectively. The variable $S_{t}$ denotes the exchange rate defined as units of local currency per dollar. For convenience, we abstract from foreign inflation so $\bar{P}_{t}^{T *}=1$ and $\bar{P}_{t}^{T}=S_{t}$.

It is well known that PPP does not hold at the level of the CPI. Here we emphasize two reasons for this failure of PPP: nontradable goods and distribution costs associated with the sale of tradable goods. With nontradable goods the CPI is given by:

$$
P_{t}=\left(P_{t}^{T}\right)^{\omega}\left(P_{t}^{N}\right)^{1-\omega}
$$

Here $\omega$ is the weight of tradable goods in the index, $P_{t}^{N}$ is the price of nontradable goods, and $P_{t}^{T}$ is the retail price of tradable goods.

We introduce distribution costs (wholesaling, retailing, and transportation) by assuming that selling one unit of the tradable good requires using $\delta$ units of the nontradable good. ${ }^{6}$ Given perfect competition in the retail sector, the retail price of tradable goods is:

$$
P_{t}^{T}=\bar{P}_{t}^{T}+\delta P_{t}^{N}
$$

As long as $\delta>0, \mathrm{PPP}$ does not hold at the retail level.

The Government's Flow Budget Constraint Government spending, other than on interest payments, consists of purchases of tradable and nontradable goods as well as transfer payments. In period $t$, the government purchases $g_{t}^{T}$ units of tradables and $g_{t}^{N}$ units of nontradables. We assume that the government purchases goods at producer prices. ${ }^{7}$ Total government purchases of goods and services, measured in dollars, are:

$$
g_{t}=\frac{\bar{P}_{t}^{T} g_{t}^{T}+P_{t}^{N} g_{t}^{N}}{S_{t}}
$$

\footnotetext{
${ }^{6}$ See Burstein, Neves and Rebelo (2002), Corsetti and Dedola (2002), and Burstein, Eichenbaum and Rebelo (2002).

${ }^{7}$ This is consistent with the empirical findings of Burstein, Neves, and Rebelo (2002).
} 
The government makes two types of transfers to domestic households: transfers indexed to the CPI, $\hat{v}_{t}$, and transfers indexed to the exchange rate, $\tilde{v}_{t}$. Total domestic transfer payments, in local currency, are $P_{t} \hat{v}_{t}+S_{t} \tilde{v}_{t}$. The government also transfers $v_{t}^{*}$ dollars to foreigners. Given these assumptions, total government transfers, measured in dollars, are:

$$
v_{t}=\frac{P_{t} \hat{v}_{t}}{S_{t}}+\tilde{v}_{t}+v_{t}^{*}
$$

The government finances its expenditures by collecting taxes, printing money, and issuing debt. We assume that the government collects taxes on the output at rate $\tau^{y}$. The dollar value of tax revenues at time $t, \tau_{t}$, is given by:

$$
\tau_{t}=\tau^{y} \frac{\bar{P}_{t}^{T} y_{t}^{T}+P_{t}^{N} y_{t}^{N}}{S_{t}}+\tau_{t}^{L}
$$

Here $y_{t}^{T}$ and $y_{t}^{N}$ denote exogenous endowments of output in the tradable and nontradable sectors, respectively, and $\tau_{t}^{L}$ represents lump-sum taxes.

The stock of domestic money is denoted by $M_{t}$. The government's seigniorage revenue at date $t$ is $\dot{M}_{t}$ in local currency or $\dot{M}_{t} / S_{t}$ in dollar terms. Throughout the paper $\dot{x}_{t}$ denotes $d x / d t$. Real money balances measured in dollars are denoted by $m_{t} \equiv M_{t} / S_{t}$.

The government can borrow and lend in dollars at a fixed interest rate, $r$. The stock of dollar-denominated bonds at time $t$ is denoted by $b_{t}$. We assume that before agents foresee any possibility of a devaluation the government issues a fixed stock of consols with a face value of $B$ units of local currency and coupon rate $r$.

The government's flow budget constraint is:

$$
\begin{array}{ll}
\Delta b_{t}=-\Delta m_{t}, & \text { if } t \in I, \\
\dot{b}_{t}=r b_{t}+r B / S_{t}+g_{t}+v_{t}-\tau_{t}-\dot{M}_{t} / S_{t}, & \text { if } t \notin I .
\end{array}
$$

As in Drazen and Helpman (1987), (2.7) takes into account the possibility of discrete changes in $m_{t}$ and $b_{t}$ at a finite set of points in time, $I$. Below we list the points in time at which these discrete changes might occur.

The Government's Lifetime Budget Constraint The flow budget constraint, (2.7), together with the condition $\lim _{t \rightarrow \infty} e^{-r t} b_{t}=0$, implies the following intertemporal budget constraint:

$$
b_{0}+\int_{0}^{\infty} \frac{r B}{S_{t}} e^{-r t} d t=\int_{0}^{\infty}\left(\tau_{t}-g_{t}-v_{t}\right) e^{-r t} d t+\int_{0}^{\infty} \frac{\dot{M}_{t}}{S_{t}} e^{-r t} d t+\sum_{i \in I} e^{-r i} \Delta m_{i} .
$$


This constraint requires that the initial dollar value of the debt plus the present value of consol payments measured in dollars be equal to the present value, in dollars, of primary surpluses plus seigniorage revenue.

A Sustainable Fixed Exchange Rate Regime We assume that, for all $t<0, S_{t}=S$ and agents believe that this fixed exchange rate regime is sustainable. In particular, we suppose agents anticipate that the government will satisfy its intertemporal budget constraint, (2.8), without abandoning the fixed exchange rate at any date $t \geq 0$. Given PPP, (2.1), this is equivalent to agents believing that the government will pursue fiscal and monetary policies consistent with zero inflation in the producer price of tradables.

To simplify, we assume that for all $t<0, g_{t}^{T}=g^{T}, g_{t}^{N}=g^{N}, \hat{v}_{t}=\hat{v}, \tilde{v}_{t}=\tilde{v}, v_{t}^{*}=v^{*}=0$, $\tau_{t}^{L}=\tau^{L}, y_{t}^{T}=y^{T}$, and $y_{t}^{N}=y^{N}$. These assumptions imply that in equilibrium the price of nontradables, the CPI, and the nominal money supply are also constant: $P_{t}^{N}=P^{N}$, $P_{t}=P=\left(S+\delta P^{N}\right)^{\omega}\left(P^{N}\right)^{1-\omega}$ and $M_{t}=M$. Agents believe that these variables will continue to be constant for $t \geq 0$. Under these assumptions the government's lifetime budget constraint reduces to:

$$
b_{0}+\frac{B}{S}=\frac{\tau-g-v}{r} .
$$

Here $\tau, g$, and $v$ are constants given by (2.4), (2.5), and (2.6). Equation (2.9) requires that the present value of current and future real primary surpluses equals the initial real net liabilities of the government.

A Crisis At $t=0$ agents learn that the government will have to increase its future dollar transfers to domestic residents and foreigners, say, because of loan guarantees to the creditors of failing banks. We denote by $\phi$ the dollar present value of these increased transfers:

$$
\phi=\int_{0}^{\infty}\left(\tilde{v}_{t}-\tilde{v}+v_{t}^{*}-v^{*}\right) e^{-r t} d t
$$

We assume that these new transfers will not be financed with an explicit fiscal reform. By such a reform we mean changes in $g_{t}^{T}, g_{t}^{N}, \hat{v}_{t}$, or $\tau^{y}$ that would offset the effects of the increase in dollar transfers. As shown below, this implies that the fixed exchange rate regime must be abandoned.

At time zero agents also learn the new paths of tradable and nontradable output. We assume that tax rates, as opposed to tax revenues, remain constant. This assumption is 
consistent with the observation that explicit tax reforms are relatively minor in the aftermath of currency crises.

To see the impact of the crisis on the government's lifetime budget constraint we use (2.9) to re-write (2.8) as:

$$
\begin{aligned}
\phi= & \int_{0}^{\infty}\left(\tau_{t}-\tau\right) e^{-r t} d t+\int_{0}^{\infty}\left(g-g_{t}\right) e^{-r t} d t+\int_{0}^{\infty}\left(\frac{P \hat{v}}{S}-\frac{P_{t} \hat{v}_{t}}{S_{t}}\right) e^{-r t} d t \\
& +\left[\frac{B}{S}-\int_{0}^{\infty} \frac{r B}{S_{t}} e^{-r t} d t\right]+\left[\int_{0}^{\infty} \frac{\dot{M}_{t}}{S_{t}} e^{-r t} d t+\sum_{i \in I} e^{-r i} \Delta m_{i}\right] .
\end{aligned}
$$

According to (2.10), the present value of the increase in transfers must be financed by changes in the dollar value of: (i) tax revenues; (ii) government expenditures; (iii) CPIindexed transfers; (iv) nonindexed debt; and (v) seigniorage revenues. We discuss each of these components in turn.

Since we excluded explicit fiscal reforms, the only way in which the government can satisfy its intertemporal budget constraint is to use monetary policy to generate depreciationrelated revenues. ${ }^{8}$ To see this, suppose for the moment that the fixed exchange rate could be sustained once new information about higher deficits arrived. Then the money supply would never change and the government could not collect any seigniorage revenues. This in conjunction with the fact that the price level would be fixed, implies that all of the terms on the right hand side of (2.10) would equal zero. ${ }^{9}$ But then the government's budget constraint would not hold which contradicts the assumption that the fixed exchange rate regime is sustainable. We conclude that the government must at some point move to a floating exchange rate system or, at least, abandon its peg at the fixed rate $S$.

\footnotetext{
${ }^{8}$ The government can also explicitly default on outstanding debt. We ignore this possibility since we are interested in episodes in which explicit default did not occur. International bailouts are an additional source of crisis financing, but in practice the value of these bailouts is not very significant. See Jeanne and Zettelmeyer (2000) who show that the subsidy component of IMF programs is quite small.

${ }^{9}$ This statement assumes that tax revenue does not change absent a devaluation.
} 


\section{Tax Effects}

The change in the present value of tax revenues is given by:

$$
\int_{0}^{\infty}\left(\tau_{t}-\tau\right) e^{-r t} d t=\int_{0}^{\infty} e^{-r t}\left[\tau^{y}\left(y_{t}^{T}+y_{t}^{N} P_{t}^{N} / S_{t}\right)+\tau_{t}^{L}\right] d t-\tau / r .
$$

Recall that we assumed tax rates are constant. If $y_{t}^{N}, y_{t}^{T}$, and $\tau_{t}^{L}$ were constant and $P_{t}^{N} / S_{t}$ did not change, this term would be zero. We do not expect either of these conditions to hold, in general. First, large devaluations are typically followed by significant changes in the output of the tradable and nontradable sectors. Second, as documented in Table 3, devaluations are also followed by large drops in the dollar price of nontradable goods. These effects can lead to either a fiscal improvement or a fiscal deterioration. For example, a drop in the value of nontradable output $\left(P_{t}^{N} y_{t}^{N} / S_{t}\right)$ induces a decline in real tax revenues, thus exacerbating the fiscal consequences of the initial crisis. On the other hand, if most tax revenue comes from the tradable sector and this sector booms after a devaluation, there could be a net rise in the present value of tax revenues.

\section{Government Purchases Effects}

The change in the present value of government purchases is given by:

$$
\int_{0}^{\infty}\left(g-g_{t}\right) e^{-r t} d t=\int_{0}^{\infty}\left(g^{T}-g_{t}^{T}+\frac{P^{N}}{S} g^{N}-\frac{P_{t}^{N}}{S_{t}} g_{t}^{N}\right) e^{-r t} d t
$$

Suppose that $g_{t}^{T}$ and $g_{t}^{N}$ remain constant at their pre-crisis values. If $P_{t}^{N} / S_{t}$ also remained constant then the term above would be zero. But a drop in $P_{t}^{N} / S_{t}$ generates an automatic decline in the dollar value of government spending on nontradable goods. This type of automatic fiscal reform is important because most government purchases are on nontradables, such as health and education.

\section{Government Transfers Effects}

The change in the present value of CPI-indexed government transfers is given by:

$$
\int_{0}^{\infty}\left(\frac{P \hat{v}}{S}-\frac{P_{t} \hat{v}_{t}}{S_{t}}\right) e^{-r t} d t
$$

Suppose $\hat{v}_{t}$ remained constant at its pre-crisis value. If $P_{t} / S_{t}$ also remained constant then the term above would be zero. But any drop in $P_{t} / S_{t}$ generates an automatic decline in the dollar value of CPI-indexed transfers. 


\section{Nonindexed Debt Effects}

The reduction in the dollar value of nonindexed debt is given by:

$$
\frac{B}{S}-\int_{0}^{\infty} \frac{r B}{S_{t}} e^{-r t} d t .
$$

Other things equal, a devaluation generates an implicit fiscal reform by reducing the value of this debt. This channel has been emphasized in the literature on the fiscal theory of the price level. ${ }^{10}$

\section{Seigniorage Effects}

The dollar value of seigniorage is given by:

$$
\begin{gathered}
\int_{0}^{\infty} \dot{M}_{t} / S_{t} e^{-r t} d t+\sum_{i \in I} e^{-r i} \Delta m_{i} \\
\text { Post-Crisis Inflation }
\end{gathered}
$$

The post-crisis behavior of inflation depends critically on the financing mix chosen by the government. For example, suppose that the government could pay for most of its fiscal costs by reducing the dollar value of outstanding nominal debt with a devaluation at time zero. Then the currency crisis would be associated with little future money growth or longrun inflation. In contrast, suppose that the government financed most of the new transfers with seigniorage revenues. This financing strategy would have very different implications for money growth and inflation.

It is also clear that post-crisis inflation rates depend on the types of goods that the government purchases and on the nature of the tax system. Suppose, for example, that the government raises most of its tax revenues from the nontradable sector and the dollar value of production in this sector falls precipitously after a devaluation. Then a devaluation would magnify the initial fiscal crisis so that money growth rates and inflation would be higher than otherwise. In contrast, suppose that most government spending is devoted to nontradable goods. Then a crisis which leads to a decline in $P_{t}^{N} / S_{t}$ generates a fiscal improvement.

To go beyond these general statements and formally analyze the implications of different financing strategies, we must embed the government's budget constraint into a fully articulated model.

\footnotetext{
${ }^{10}$ See footnote 3 for related references.
} 


\section{The Model}

The representative agent maximizes lifetime utility, defined as:

$$
U=\int_{0}^{\infty} \frac{\left[\left(c_{t}^{T}\right)^{\omega}\left(c_{t}^{N}\right)^{1-\omega}\right]^{1-\sigma}-1}{1-\sigma} e^{-\rho t} d t
$$

Here $c_{t}^{T}$ and $c_{t}^{N}$ denote the consumption of tradables and nontradables, respectively. In addition $\rho>0$ is the discount factor and $\sigma>0$ is the inverse of the elasticity of intertemporal substitution.

The representative agent can borrow and lend in international capital markets at a constant real interest rate $r$. To eliminate trends in the current account we assume that $r=\rho$. The representative agent's flow budget constraint for $t \geq 0$ is given by:

$$
\begin{array}{ll}
\Delta f_{t}=-\Delta m_{t} & \text { if } t \in I, \\
\dot{f}_{t}=r f_{t}+r B / S_{t}+y_{t}+\hat{v}_{t} P_{t} / S_{t}+\tilde{v}_{t}-\left(P_{t}^{T} c_{t}^{T}+P_{t}^{N} c_{t}^{N}\right) / S_{t}-\tau_{t}-\dot{M}_{t} / S_{t} & \text { if } t \notin I .
\end{array}
$$

Here $f_{t}$ denotes the net foreign assets held by the representative agent and $y_{t}=y_{t}^{T}+y_{t}^{N} P_{t}^{N} / S_{t}$ represents the dollar value of the household's endowments of tradable and nontradable goods. As with the government, the household's budget constraint (3.2) takes into account the possibility of discrete changes in $m_{t}$ and $f_{t}$ at a finite set of points in time, $I$. The flow budget constraint, together with the condition $\lim _{t \rightarrow \infty} e^{-r t} f_{t}=0$, implies the following intertemporal budget constraint for the household:

$$
\begin{aligned}
& f_{0}+\int_{0}^{\infty} e^{-r t}\left(y_{t}+P_{t} \hat{v}_{t} / S_{t}+\tilde{v}_{t}+r B / S_{t}\right) d t= \\
& \int_{0}^{\infty} e^{-r t}\left(P_{t}^{T} c_{t}^{T} / S_{t}+P_{t}^{N} c_{t}^{N} / S_{t}+\tau_{t}+\dot{M}_{t} / S_{t}\right) d t+\sum_{i \in I} e^{-r i} \Delta m_{i} .
\end{aligned}
$$

According to (3.3), when measured in dollars, the household's initial assets plus the present value of endowment and transfer income must equal the present value of expenditures inclusive of taxes and changes in money balances.

Finally, the representative agent faces the following continuous time analogue to a cashin-advance constraint on consumption purchases: ${ }^{11}$

$$
\eta\left(P_{t}^{T} c_{t}^{T}+P_{t}^{N} c_{t}^{N}\right) \leq M_{t}
$$

The constant $\eta$ allows the model to generate empirically plausible predictions for average velocity. Since the nominal interest rate is positive in all the scenarios that we consider, (3.4) holds with strict equality.

\footnotetext{
${ }^{11}$ See Feenstra (1985) for a discussion of cash-in-advance constraints in continuous time models.
} 
The problem of the representative household is to maximize (3.1) subject to (3.2) and (3.4) by choice of time paths for $c_{t}^{T}, c_{t}^{N}, m_{t}$ and $f_{t}$ given known time paths for $S_{t}, P_{t}^{N}, P_{t}^{T}$ and $P_{t} .^{12}$

The market clearing condition for nontradable goods is:

$$
y_{t}^{N}=c_{t}^{N}+\delta c_{t}^{T}+g_{t}^{N}
$$

where $\delta c_{t}^{T}$ are the nontradable goods used in the process of distributing tradable goods.

Using this equation and consolidating the resource constraints of the government and the household, we obtain the aggregate intertemporal resource constraint for tradable goods:

$$
f_{0}-b_{0}+\int_{0}^{\infty} e^{-r t} y_{t}^{T} d t=\int_{0}^{\infty} e^{-r t}\left(c_{t}^{T}+g_{t}^{T}+v_{t}^{*}\right) d t
$$

\subsection{The Exchange Rate Crisis}

Prior to time zero, agents anticipate zero inflation and the economy is in a steady state with constant values of $S, y^{T}, y^{N}, g^{T}$ and $g^{N}$. In the Technical Appendix we show that this implies that $P_{t}^{N}, c_{t}^{T}$ and $c_{t}^{N}$ are constant over time. At time zero agents learn about the new government transfers that make the fixed exchange rate regime unsustainable.

To characterize the time at which the fixed exchange rate regime collapses and the postcrisis behavior of the economy, we make particular assumptions about government policy. Here there are two possibilities. First, we can specify a post-crisis monetary policy and a rule for abandoning the fixed exchange rate. Second, we can specify a path for the exchange rate and then reverse engineer a path for monetary policy that can support the exchange rate path as an equilibrium. Computing this reverse mapping is difficult in our context since we have to ensure that the government's intertemporal budget constraint holds. For this reason we followed the first strategy which has the additional advantage of preserving a tight link with the large literature on currency crises.

\section{Abandoning the Fixed Exchange Rate}

We assume that the government floats the currency at the first point in time, $t^{*}$, when net debt reaches some finite upper bound or, equivalently, when the domestic money supply falls by $\chi$ percent of the initial money supply. We work with this rule for three reasons.

\footnotetext{
${ }^{12}$ In the Technical Appendix we describe the solution to a discrete time version of the household's problem which limits to the solution of the continuous time problem as the interval between time periods goes to 0 .
} 
First, it is a good description of what actually happens in a currency crisis. Second, it can be interpreted as a short-run borrowing constraint on the government. Finally, Rebelo and Végh (2002) show that this rule can be optimal for an interesting class of economies.

\section{Post-Crisis Monetary Policy}

For simplicity we assume that the government will raise seigniorage revenues by a combination of a one time increase in the stock of money at time $T$ to a level $M_{T}$ and growth in the money supply at rate $\mu$ from period $T$ on. So the path of $M_{t}$ is given by:

$$
M_{t}=M_{T} e^{\mu(t-T)}, \text { for } t \geq T \text {. }
$$

Given $T$, the pair $\left(M_{T}, \mu\right)$ must satisfy the government's budget constraint.

\section{Computing the Time of the Speculative Attack}

In order to solve for the time of the speculative attack, we must compute the dynamic perfect foresight equilibrium. Our procedure is as follows. First, we fix the parameters of monetary policy $\left(\chi, T, M_{T}\right.$ and $\mu$ ). Second, we derive the equilibrium paths of consumption, inflation, and the exchange rate. Third, we check whether the government's budget constraint is satisfied. If not, we adjust either $M_{T}$ or $\mu$ and recompute the equilibrium. We repeat this procedure until we have converged upon a solution. Details of this procedure are provided in the Technical Appendix. In computing the equilibrium we allow for discontinuities in consumption, real balances, and government debt at the following points: (i) time zero, when the new information arises; (ii) the time of the speculative attack $\left(t^{*}\right)$; and (iii) the time at which monetary policy changes $(T)$.

\section{Properties of the Model}

In this section we discuss the properties of a version of our model calibrated to Korean data. We do so with four objectives in mind. First, we ascertain whether this model can generate low inflation rates in conjunction with high rates of depreciation. Second, we use the model to study the implications of different financing strategies for the government. Third, we deconstruct the model to understand how it accounts for post-crisis inflation and exchange rates. Finally, our analysis serves as a useful backdrop for our case study of Korea. 


\subsection{Calibration of the Model}

Table 4 summarizes our assumptions about parameter values. We set $\sigma=1$, so that utility is logarithmic. We set $r$ equal to $0.055 .{ }^{13}$ We normalize the initial exchange rate to $S=1$. Without loss of generality we set $y^{T}=y^{N}=1$. This implies that the level of real GDP is $y=1+p^{N}$, where $p^{N}=P^{N} / S$ is the dollar price of nontradable goods.

Our data for Korea suggest that the share of tradable goods in GDP, $s^{T}$, is roughly $0.35 .{ }^{14}$ Since the share of tradable goods in GDP is $s^{T}=1 /\left(1+p^{N}\right), p^{N}$ must be equal to 1.86 .

Between 1993 and 1997 government purchases averaged about 15.3 percent of GDP in Korea. So we set $g=0.153 y$. We estimate that roughly 13.2 percent of government purchases are tradable goods, implying $g^{T}=0.132 g$ and $g^{N}=\left(g-g^{T}\right) / p^{N}$. We set initial transfers to foreigners, $v^{*}$, equal to 0 . In the Technical Appendix we show that the steady state value of net foreign assets, $f_{0}$, the consumption of tradables, $c^{T}$, and the consumption of nontradables, $c^{N}$, are uniquely pinned down given the values of $y^{T}, y^{N}, g^{T}, g^{N}, v^{*}$, and $p^{N}$ that we have already chosen.

In the four years prior to Korea's crisis, the average ratio of the monetary base to GDP was 0.067 . We set $\eta$ so that the ratio of the monetary base to GDP in the initial steady state is consistent with this value. ${ }^{15}$

Below we argue that the pre-crisis ratio of taxes to GDP in Korea was roughly 0.213. Accordingly, we set $\tau^{y}=0.213$. The ratio of spending on transfers to GDP averaged 0.043 for the period 1993 to 1997 . So we set steady state transfers, $v$, equal to $0.043 y$. We assume that total transfers, $v_{t}$, represent 4.3 percent of GDP in the steady state $(v=0.043 y)$, which corresponds to the average ratio of transfers to GDP from 1993 to 1997. The steady-state value of CPI-indexed transfers $(P \hat{v} / S)$ is set equal to $0.027 y$, or 2.7 percent of GDP. This allows the model to generate an amount of revenue from the reduction in the dollar value of transfers that is consistent with our empirical estimates for Korea presented in section 5.

To calibrate $b_{0}$ we used data on the real consolidated foreign debt of the government and central bank. The Korea Institute for International Economic Policy (http://kiep.go.kr) estimates that the foreign debt of the public sector in June 1997 was equal to 2 trillion won. According to the International Financial Statistics (IFS), the value of the central bank's net

\footnotetext{
${ }^{13}$ Calibrating the dollar interest rate for Korea is difficult because most internal lending is denominated in won for regulatory reasons. We found that, across a wide variety of domestic instruments, the dollar rate of return, while volatile, averaged between 5 and 6 percent in the period 1991 to 2002 .

${ }^{14}$ This is the average share of agriculture, forestry, mining, and manufacturing in Korean GDP for 1993-97.

${ }^{15}$ The value of $\eta$ is given by $\eta=0.067 y /\left[\left(1+\delta p^{N}\right) c^{T}+p^{N} c^{N}\right]$.
} 
foreign assets was approximately 28 trillion won. This suggests that the net foreign assets of the consolidated public sector was roughly equal to 26 trillion won or 5.7 percent of 1997 GDP. So we set $b_{0}$ equal to $-0.057 y$.

Nominal debt in the model $(B)$ is a perpetuity, so its duration is different from that of Korea's debt. For this reason it is not appropriate to use the measured stock of nonindexed debt on the eve of the crisis to calibrate $B$. We set $B=0.075 y$ so that the revenue from debt deflation is commensurate with our empirical estimates described in section 5 . We choose the level of lump sum taxes, $\tau^{T}$, to ensure that the government's lifetime budget constraint, (2.9), holds in the initial steady state of our model. ${ }^{16}$

We now turn to the parameters that govern post-crisis monetary policy. We identify period zero as the end of June 1997, when the Thai banking crisis culminated in a currency crisis. Like Thailand, Korea was undergoing a severe crisis in its banking industry. For our purposes it seems reasonable to assume that the outbreak of the Thai crisis led Koreans to anticipate that they too would undergo a currency crisis. ${ }^{17}$ This crisis occurred at the end of October 1997, roughly 4 months after the Thai crisis. Given the difficulty of obtaining direct evidence on the value of $\chi$ we set this parameter so that the speculative attack occurs four months after time zero. We set the time at which there is a remonetization, $T$, to 0.5 (this corresponds to the end of December 1997). To abstract from month-to-month variation in the monetary base we set $M_{T} / M=1.12$. This value corresponds to the ratio of the average monetary base in November 1997-January 1998 to the average monetary base in May-July 1997. Finally, we solve the model to endogenously determine the steady state money growth rate, $\mu$, that is consistent with the government's intertemporal budget constraint.

According to Standard and Poor's (2000) the cost of the banking sector bailout was about 24 percent of 1997 GDP. In our case study of Korea below, we estimate that: (i) output losses due to the recession induced losses of tax revenue amounting to 10.2 percent of GDP; (ii) to date, explicit fiscal reforms have equaled roughly 11.9 percent of GDP; and (iii) future explicit fiscal reforms will yield an additional 8.8 percent of GDP. Once we add these costs to the bailout costs and net the fiscal reforms from this total, the amount that needs to be financed from depreciation-related revenue is about 13.5 percent of GDP. Hence we set $\phi=0.135 y$.

We set $\omega=0.5$ to match the weight that tradables receive in the Korean CPI. Nontradable

\footnotetext{
${ }^{16}$ Specifically, $\tau^{L}$ is given by $\tau^{L}=r\left(b_{0}+B / S\right)+g+v-\tau^{y}\left(y^{T}+p^{N} y^{N}\right)$.

${ }^{17}$ See Corsetti, Pesenti, and Roubini (1999) and Burnside, Eichenbaum, and Rebelo (2001).
} 
goods affect the predictions of the model only if there is a change in the dollar price of nontradable goods after a crisis. Here we pursue a simple strategy to generate such a change: consistent with the data, we assume that the domestic currency price of nontradables remains constant for two months after the crisis and then starts growing at the rate of depreciation. ${ }^{18}$ In the presence of these nominal rigidities the market for nontradable goods does not clearthere is excess demand for nontradable goods. We make the simplifying assumption that nontradables are rationed and there is no resale market for these goods. While admittedly stark, this modeling strategy allows us to capture, in a parsimonious way, the effects of a fall in the price of nontradable goods without fully modeling the production side of the economy.

Finally, we set the distribution cost parameter $\delta$ to 0.5 . This implies that the pre-crisis distribution margin is 50 percent which is within the range of estimates presented in Burstein, Neves, and Rebelo (2002). ${ }^{19}$

\subsection{The Benchmark Model}

Figure 1(a) depicts the equilibrium paths for the exchange rate, the CPI, the rate of depreciation, the rate of inflation, the level of the money supply, and real balances. Four key features of Figure 1(a) are worth noting. First, as in Burnside, Eichenbaum, and Rebelo (2001), the speculative attack happens after agents learn about deficits, but before new monetary policy is implemented. So the attack is unpredictable on the basis of classical fundamentals such as past deficits or inflation. Second, inflation rises in the wake of the exchange rate collapse, well before the change in monetary policy. As in Sargent and Wallace (1981), this reflects agents' anticipation of the increase in money supply that takes place at time $T$. Third, there is a discrete drop in the money supply at the time of the attack. This reflects agents' decisions to exchange their domestic money holdings for dollars at the fixed exchange rate. It is this drop in the money supply that triggers the threshold rule and leads the government to abandon the fixed exchange rate regime. Fourth, there is a large wedge between the rate

\footnotetext{
${ }^{18}$ There are several mechanisms through which a fall in the dollar price of nontradables can occur. In Burstein, Eichenbaum, and Rebelo (2002) the dollar price of nontradables falls because of a drop in consumption after a currency crisis that is induced by a tightening of agents' external borrowing constraints. In their model agents reduce the production and consumption of nontradable goods and use the corresponding resources to increase the production of exported goods. Because certain factors like capital are fixed in the short run, the marginal (dollar) cost of producing nontradable goods is an increasing function of total output. Other things equal, the fall in the production of nontradable goods induces a decline in their dollar price. More generally, any negative wealth effect associated with a currency crisis could generate similar effects.

${ }^{19}$ The distribution margin is the fraction of the retail price that represents distribution costs. In our notation this is given by: $\delta P_{t}^{N} /\left(\bar{P}_{t}^{T}+\delta P_{t}^{N}\right)$.
} 
of inflation and the rate of depreciation.

Table 5(a) summarizes the key implications of the model for inflation, depreciation, and government financing in the wake of the crisis. A number of results are worth noting. First, inflation in the first year after the crisis is only 12.7 percent, while long run inflation is only 2.0 percent. Inflation in the first year is higher than the 7.2 percent observed in the data. However, Burstein, Eichenbaum, and Rebelo (2002) argue that there was a significant downward bias in measured Korean inflation. ${ }^{20}$ While it is difficult to provide precise measures of this bias, it is clear that taking it into account would move the model closer into conformity with reality. Second, despite the low rate of inflation the rate of depreciation in the model is 46.5 percent, more than three times higher than inflation in the first year after the crisis.

In terms of government financing seigniorage accounts for only 2.0 percent of pre-crisis GDP, or less than 10 percent of total depreciation-related revenues. By far the most important source of depreciation-related revenues is the fall in the dollar value of transfers (11.1 percent of pre-crisis GDP). This decline reflects the large wedge between the CPI and the exchange rate that arises in the immediate aftermath of the crisis.

Viewed overall our results imply that the government can satisfy most of its financing needs by relying on an implicit fiscal reform. We conclude that the model is consistent with the observation that many large devaluations are associated with low rates of inflation and that seigniorage plays a modest role in government financing.

\subsection{Implications of Alternative Financing Scenarios}

In this subsection we use the benchmark model to assess the implications of three alternative financing scenarios. First, suppose that there is no outstanding nominal debt at the onset of the crisis $(B=0)$ so that there are no revenues from debt deflation. In addition, assume that the government makes up for this shortfall in revenue by increasing the steady state growth rate of money. As Table 5 indicates, this alternative financing scenario implies a modest rise in short-run inflation (from 12.7 to 16.4 percent) and to a twofold increase in long run inflation (from 2 to 6 percent).

\footnotetext{
${ }^{20}$ According to Burstein, Eichenbaum, and Rebelo (2002) the bias in the official figures reflects the fact that, after contractionary currency crises, consumers switch from high quality imports to lower quality domestic substitutes. In principle this 'flight from quality' should not affect measured inflation since the CPI measures the price of a fixed bundle of goods. However, in practice, the individual items that comprise the CPI basket are replaced to reflect changes in consumption patterns. This can impart a significant downward bias in measured inflation.
} 
Second, suppose that all transfers are indexed to the dollar. In this case the government does not benefit from a reduction in the dollar value of transfers. As above, we assume that the government makes up for this shortfall in revenue by raising the steady state growth rate of money. Table 5 shows that this alternative financing scenario leads to markedly different implications for post-crisis inflation and exchange rates. Relative to the benchmark scenario inflation in the first year after the crisis rises from 12.7 to 22.5 percent. Steady state inflation rises from 2 to 12.7 percent. The rate of depreciation in the first year after the crisis climbs from 46.5 to 60.3 percent.

Third, for completeness we eliminate revenues from both debt deflation and reductions in the dollar value of transfers. Not surprisingly, under this scenario, inflation is very large both in the first year after the crisis (29.2 percent) and in the long run (20.1). Moreover the rate of exchange rate depreciation rises to almost 70 percent.

These experiments make clear that post-crisis rates of inflation and depreciation depend critically on the sources of depreciation-related revenue available to a government. In this sense the model is consistent with heterogeneity in post-crisis inflation and devaluation rates.

\subsection{Deconstructing the Benchmark Model}

In this subsection we use a sequence of numerical examples to document which features of our model allow it to account for the post-crisis behavior of inflation, exchange rates and seigniorage.

\section{A Simple Textbook Model}

We begin by eliminating all the features that distinguish our model from the simple textbook setup. Specifically, we assume that there is no local currency debt $(B=0)$, all goods are tradable $(\omega=1)$, prices are perfectly flexible, and there are no distribution costs $(\delta=0)$. Given these assumptions PPP holds at the level of the CPI, so that the price level coincides with the exchange rate. Also, the only depreciation-related source of revenue is seigniorage.

Figure 1(b) depicts the equilibrium paths for the exchange rate, the CPI, the rate of depreciation, the rate of inflation, the level of the money supply, and real balances. Table 5 (e) summarizes the key implications of the model. A number of results are worth noting. First, the rate of inflation in the first year after the crisis is counterfactually large: 23.3 
percent. Second, the long run rate of inflation, 11.5 percent, is also counterfactually large. Third, inconsistent with the data, the rate of inflation coincides with the rate of depreciation.

\section{Introducing Nominal Debt}

Table 5(f) displays the impact of incorporating nominal government debt into the simple textbook model. Inflation in the first year after the crisis falls from 23.3 percent in the benchmark model to 19.6 percent. Long run inflation declines from 11.5 percent to 7.3 percent. Mirroring these results, seigniorage is now 9.1 percent of GDP, or about two-thirds of total depreciation-related revenues. While this version of the model performs better than the simple textbook model, it still suffers from important shortcomings: inflation is counterfactually large and the rate of depreciation is too low relative to the data.

\section{Introducing Nontradable Goods with Sticky Prices}

We now incorporate nontradable goods into the previous model. As in our benchmark analysis, we assume that the price of these goods is sticky. Table 5(g) summarizes the properties of this version of the model. The key difference between this example and the previous case is that the rates of depreciation and inflation are no longer the same. Now the rate of depreciation in the first year after the crisis (34.2 percent) is much larger than the rate of inflation during the same period (20.3 percent).

\section{Introducing CPI-indexed Transfers}

We now add, to the previous version of the model, government transfers that are indexed to the CPI [see Table 5(h)]. The key impact of this change is that the importance of seigniorage as a source of government finance drops - it now amounts to 6.2 percent of pre-crisis GDP. Since seigniorage is less important, inflation declines to 16.4 percent in the first year after the crisis and to 5.4 percent in the new steady state. The problem is that the rate of depreciation in the first year declines to only 29.7 percent.

\section{Introducing Distribution Costs}

Once we add distribution costs we are back to our benchmark model. Distribution costs improve the performance of the model along two key dimensions. First, the model does a much better job of accounting for the wedge between the rate of inflation and the rate of depreciation. Second, seigniorage plays a much smaller role in government financing while the fall in the dollar value of the transfers plays a large role. 
To summarize, introducing nonindexed debt and CPI-indexed transfers allows the model to generate low inflation rates, especially in the steady state. This is because these sources of revenue reduce the government's need to rely on seigniorage revenues. Introducing nontradable goods and distribution costs allows the model to generate large devaluations along with low rates of inflation. In combination these features allow the model to account for the salient features of data on post-crisis seigniorage, inflation and devaluation rates.

\section{Case Studies: Korea, Mexico, and Turkey}

We now turn to three case studies to assess how governments actually financed the fiscal costs associated with currency crises. We use these results to assess the plausibility of our model's predictions for post-crisis rates of inflation and depreciation.

In our theoretical analysis, the government finances crisis costs via a combination of: (i) seigniorage revenues; (ii) debt deflation; (iii) reductions in the dollar value of government transfers; and (iv) reductions in the dollar value of the government's purchases net of tax revenue. In reality two other factors come into play: (v) explicit fiscal reforms that raise tax revenue or reduce spending; and (vi) revenue losses associated with post-crisis declines in real activity.

It is difficult to precisely quantify the importance of (i)-(vi). The basic problem is that one must compare actual revenues and expenditures with what they would have been absent the crisis. Inevitably, this requires relying on debatable assumptions about how economic aggregates would have evolved if a crisis had not occurred. In practice we found that the breakdown of fiscal reforms between explicit and implicit reforms is particularly sensitive to these assumptions. Even seigniorage calculations can be sensitive to the assumptions made about what money growth and depreciation rates would have been in the absence of a crisis. Nevertheless we think that our calculations are informative.

Before we turn to the details of our calculations we briefly summarize the main findings for the three countries that we study: Korea, Mexico, and Turkey. First, none of these countries have fully paid for all the costs associated with their currency crises. According to our estimates, Korea, Mexico, and Turkey have paid for roughly 43, 52 and 54 percent of the costs of their crises, respectively. Second, to date, in none of these countries has seigniorage been the dominant source of revenues. Its importance has varied from 7 percent 
of net crisis costs in the case of Mexico to roughly 10 percent in the case of Turkey. Third, debt deflation has been more important than seigniorage in all three countries, ranging from a low of 7.2 percent of the total cost in Mexico to a high of 38 percent of the total cost in Turkey. Fourth, in all cases there was a substantial decline in the dollar value of tax revenues after the crisis. but the decline in the dollar value of government purchases was important in offsetting the tax revenue decline. Finally, our estimates suggest that there were large declines in the dollar value of transfers. Indeed, in the case of Korea and Mexico this was the single most important source of revenue.

We now take to the details of our analysis and discuss our assumptions and procedures with reference to the Korean case. We then turn to the Mexican and Turkish episodes.

\subsection{Case Study of Korea}

Timing and Interest Rates We denote the month and year in which the crisis occurred by $t_{m}$ and $t_{a}$, respectively. For the Korean case we set $t_{m}$ to October 1997 and $t_{a}$ to 1997 . We make this distinction because some data is available at the monthly frequency (e.g. seigniorage revenue) while other data (e.g. government purchases of goods and services) is available only at an annual frequency.

To simplify, we assume a constant annual dollar interest rate, $r$, equal to an estimate of the average dollar interest rate for government debt. Consistent with our discussion above we set $r=0.055$ in the Korean case.

Seigniorage Revenue Recall that in our model the government cannot raise seigniorage revenue under a fixed exchange rate regime because the demand for real and nominal balances is constant. In reality governments can raise seigniorage revenues under a fixed exchange rate since the demand for real balances grows if output expands.

We measure actual seigniorage revenue, $M_{t}-M_{t-1}$, using data on the monetary base, $M_{t}$. The dollar value of seigniorage revenue, $\left(M_{t}-M_{t-1}\right) / S_{t}$, is computed using the monthly average exchange rate. We assume that, in the absence of a crisis, the money stock would have grown at a constant rate $\mu_{m}$, so that the monetary base would have been expected to be $M_{t}^{e}=M_{t_{m}}\left(1+\mu_{m}\right)^{t-t_{m}}$. Hypothetical seigniorage revenue is given by $M_{t}^{e}-M_{t-1}^{e}$. We convert these flows to dollars using a forecast of what the monthly exchange rate would have been in the absence of the crisis, $S_{t}^{e}$. We assume that $S_{t}^{e}=S_{t_{m}}\left(1+\delta_{m}\right)^{t-t_{m}}$, where $\delta_{m}$ is set equal to a forecast of what the average depreciation rate of the currency would have been in 
the absence of the crisis. $^{21}$ The increase in the present value of seigniorage revenue is given by:

$$
\text { Change in seigniorage }=\sum_{t=t_{m}+1}^{T_{m}}\left(1+r_{m}\right)^{-\left(t-t_{m}\right)}\left(\frac{M_{t}-M_{t-1}}{S_{t}}-\frac{M_{t}^{e}-M_{t-1}^{e}}{S_{t}^{e}}\right) .
$$

Here $T_{m}$ denotes the last period for which we have monthly data on the monetary base and the exchange rate, i.e., August 2002.

In the Korean case we set $\mu_{m}=0.0005$, which corresponds to the average monthly money growth rate for the period October 1993 through October 1997. In addition we set $\delta_{m}=0.0008$, which corresponds to the average monthly depreciation rate of the won between 1980 and $1997 .^{22}$

Given our assumptions, the increase in Korean seigniorage revenue between November $1997\left(t_{m}+1\right)$ and August $2002\left(T_{m}\right)$ was 8.1 billion dollars, or 1.7 percent of Korea's GDP in 1997 .

Debt Deflation To estimate the revenue from debt deflation we must measure the change in the dollar value of outstanding domestic debt as a result of the crisis. This requires data on the maturity structure of debt. Table 6 summarizes the value of the different bonds outstanding in Korea at the end of October 1997, along with information on maturities.

We do not have detailed data on the maturity of each bond. For bonds with multiple maturities we assume that there were equal quantities of each maturity outstanding in October $1997 .^{23}$ Within each maturity we assume that the number of bonds within 1 month of their maturity date is the same as the number of bonds within 2 months, 3 months, etc., of their maturity dates. ${ }^{24}$

Given these assumptions, we construct a schedule of debt payments on Korean domestic

\footnotetext{
${ }^{21}$ Many countries that experience currency crises do not literally have fixed exchange rates. So, for these countries, we must estimate a rate of depreciation that would have been consistent with the prior exchange rate regime.

${ }^{22}$ This assumption implies that in the absence of the crisis the dollar would have been worth about 1003 won at the end of 2001, compared to its actual value of 1314 won and its value of 844 won at the end of 1996.

${ }^{23}$ For example, within "Grain Securities" we assume that roughly 1.62 trillion won worth of the outstanding bonds were of 1 year, 3 year, and 5 year maturity, implying a total of 4.87 trillion won.

${ }^{24}$ For example, for 1 year "Grain Securities" we assume that there were bonds worth roughly 0.135 trillion won that were 1 month, 2 months, ..., 12 months from their maturity date at the end of October 1997 . All bonds are treated as zero coupon bonds.
} 
debt outstanding as of October 1997. Total revenue from debt deflation is given by:

Debt deflation $=\sum_{t=t_{m}+1}^{T_{s}}\left(1+r_{m}\right)^{-\left(t-t_{m}\right)} B_{t}\left(\frac{1}{S_{t}^{e}}-\frac{1}{S_{t}}\right)+\left(\frac{1}{S_{T_{m}}^{e}}-\frac{1}{S_{T_{m}}}\right) \sum_{t=T_{s}+1}^{T_{b}}\left(1+r_{m}\right)^{-\left(t-t_{m}\right)} B_{t}$.

Here $B_{t}$ denotes the debt payment to be made in month $t$. The variable $T_{b}$ denotes the period when all the outstanding debt will be paid off. The last term in the previous formula reflects revenue from debt deflation associated with debt maturing after $T_{s}$, which is equal to November 2002, the last date for which we have data on $S_{t}$.

According to our data, the total value of outstanding Korean domestic debt at the end of October 1997 was roughly 73.9 trillion won, or 16.3 percent of 1997 GDP. Our estimates imply that revenue from debt deflation was about 16.6 billion dollars or 3.5 percent of GDP. Figure 2 illustrates the time series of Korea's revenue from debt deflation from 1997 through 2001. Note that most of the revenue from debt deflation accrued in the first few months after the crisis. This fact suggests that our calculations are not very sensitive to either the precise maturity structure of the debt or the fact that our data ends before all the domestic debt has been redeemed.

Changes in Tax Revenues To measure the change in taxes due to the crisis, we compute the difference between actual tax revenues, $T_{t}$, and what taxes would have been in the absence of the crisis, $T_{t}^{e}$. We assume that actual dollar tax revenue is given by $T_{t}=T_{t}^{L}+\tau p_{t} Y_{t}$, where $T_{t}^{L}$ denotes lump sum taxes, $Y_{t}$ is real GDP, $p_{t}=P_{t} / S_{t}$, and $P_{t}$ is the GDP deflator. ${ }^{25}$ The presence of lump-sum taxes allows us to capture, in a simple way, the fact that tax revenues are not perfectly correlated with GDP. We assume that, up to an i.i.d. error, lump-sum taxes are proportional to trend GDP, i.e., $T_{t}^{L}=\left(\tau^{L}+\epsilon_{t}^{L}\right) \bar{p}_{t} \bar{Y}_{t}$, where $\bar{p}_{t}$ and $\bar{Y}_{t}$ are the fitted values from log-linear trends fit to $p_{t}$ and $Y_{t}$ over the period 1980-97.

We assume that in the absence of the crisis, tax revenue would have been expected to be $T_{t}^{e}=\left(\tau^{L}+\tau\right) p_{t}^{e} Y_{t}^{e}$. Here $p_{t}^{e}$ and $Y_{t}^{e}$ denote the pre-crisis expected values of $p_{t}$ and $Y_{t}$. For Korea we set $p_{t}^{e}$ and $Y_{t}^{e}$ equal to the projections implied by log-linear trends fit to $p_{t}$ and $Y_{t}$ over the period 1980-97. These projections are illustrated in Figures 3(a) and 3(b).

The total change in tax revenue due to the crisis is defined as:

$$
\Delta(T)=\sum_{t=t_{a}+1}^{T_{a}}(1+r)^{-\left(t-t_{a}\right)}\left(T_{t}-T_{t}^{e}\right)
$$

${ }^{25}$ Notice that $p_{t} Y_{t}$ is GDP measured in current dollars. 
Here $T_{a}$ denotes the last period for which we have annual fiscal data, 2001.

To compute $\Delta(T)$ we need estimates of $\tau^{L}$ and $\tau$. Assuming that $\epsilon_{t}^{L}$ is uncorrelated with $\left(p_{t} Y_{t}\right) /\left(\bar{p}_{t} \bar{Y}_{t}\right)$, we can estimate $\tau^{L}$ and $\tau$ by regressing $T_{t} /\left(\bar{p}_{t} \bar{Y}_{t}\right)$ on a constant and $\left(p_{t} Y_{t}\right) /\left(\bar{p}_{t} \bar{Y}_{t}\right)$. Doing so over the period 1980-97 yields $\tau^{L}=0.047$ and $\tau=0.166$.

Next, we decompose $\Delta(T)$ into three components: (i) an output effect; (ii) a relative price effect; and (iii) a residual effect that we ascribe to explicit fiscal reform. We define the change in tax revenue due to changes in output as follows:

$$
\Delta(T, Y)=\sum_{t=t_{a}+1}^{T_{a}}(1+r)^{-\left(t-t_{a}\right)} \tau p_{t}^{e}\left(Y_{t}-Y_{t}^{e}\right) .
$$

Note that in this expression changes in tax revenue are due solely to the effect of the crisis on output. We define the change in tax revenue due to changes in relative prices as:

$$
\Delta(T, p)=\sum_{t=t_{a}+1}^{T_{a}}(1+r)^{-\left(t-t_{a}\right)} \tau\left(p_{t}-p_{t}^{e}\right) Y_{t} .
$$

This expression isolates the impact on tax revenue of changes in $p_{t}$ associated with the crisis. The residual component, or explicit fiscal reform, is given by:

$$
\Delta(T, e)=\Delta(T)-\Delta(T, Y)-\Delta(T, p)
$$

Figure 4(a) illustrates the actual path of government revenue in Korea along with the projected path implied by our calculations. Consistent with conventional wisdom, we find that the crisis led to a large decline in the dollar value of tax revenues, both because of the output effect and the relative price effect. Specifically, we estimate that through 2001 Korean tax revenues fell by 192.5 billion dollars as a result of the crisis. Of this total, 48.7 billion dollars were due to output losses and 174.0 billion dollars were due to the change in relative prices. These two effects were offset by explicit revenue increases amounting to about 30.1 billion dollars.

Changes in Government Purchases of Goods and Services Let $G_{t}$ denote the dollar value of the actual flow of government purchases of goods and services. We assume that in the absence of the crisis the dollar value of the flow of government purchases would have been $G_{t}^{e} \equiv g p_{t}^{e} Y_{t}^{e}$. Here, $g$ represents a trend share of government purchases to GDP. The change in the value of government purchases of goods and services due to the crisis is:

$$
\Delta(G)=\sum_{t=t_{a}+1}^{T_{a}}(1+r)^{-\left(t-t_{a}\right)}\left(G_{t}-G_{t}^{e}\right) .
$$


For Korea, we set $g=0.153$ which corresponds to the ratio of government purchases to GDP in the period 1993-97.

We decompose the change in government purchases into two components: (i) a relative price effect; and (ii) a residual effect that we ascribe to explicit fiscal reform. The change in government purchases due to changes in relative prices is given by:

$$
\Delta(G, p)=\sum_{t=t_{a}+1}^{T_{a}}(1+r)^{-\left(t-t_{a}\right)} g\left(p_{t}^{G}-p_{t}^{e}\right) \bar{Y}_{t} .
$$

Here $p_{t}^{G}=P_{t}^{G} / S_{t}$ and $P_{t}^{G}$ is the deflator for government purchases from the national income accounts. ${ }^{26}$ Note that this expression isolates the changes in government purchases that are due to movements in relative prices. The residual component, or explicit change in government purchases, is:

$$
\Delta(G, e)=\Delta(G)-\Delta(G, p)
$$

Figure 4(c) illustrates the actual path of government purchases in Korea along with the projected path implied by our calculations. We estimate that through 2001 the Korean government saved 191.6 billion dollars on its purchases as a result of the crisis. Of this total, 159.2 billion dollars were due to the change in relative prices, while 32.4 billion dollars were due to explicit cuts in spending.

These calculations demonstrate the quantitative importance of the fall in the relative price of nontradables on the government's fiscal position. In the Korean case this effect goes a long way in offsetting the impact of the crisis on tax revenues emphasized in the literature. Focusing on the tax effects while ignoring the expenditure effects greatly overstates the adverse effect of the crisis on the government's fiscal position.

Changes in Spending on Transfers Let $v_{t}$ be actual spending on transfers measured in dollar terms. Recall that in the model we assumed that some transfers are explicitly denominated in dollars while others are explicitly denominated in local currency. Here we assume that total transfer spending (measured in dollar terms) is given by:

$$
v_{t}=\left(\bar{\psi} \bar{p}_{t}+\psi \frac{\bar{P}_{t}}{S_{t}}\right) \bar{Y}_{t}+\bar{p}_{t} \bar{Y}_{t} \epsilon_{t}^{v}=\left(\bar{\psi}+\psi \frac{\bar{S}_{t}}{S_{t}}+\epsilon_{t}^{v}\right) \bar{p}_{t} \bar{Y}_{t}
$$

where $\bar{P}_{t}$ and $\bar{S}_{t}$ are the fitted values from log-linear trends fit to $P_{t}$ and $S_{t}$ over the period 1980-97. Recall that $\bar{p}_{t}$ is the log-linear trend for $p_{t}$. We assume that $v_{t}$ is proportional

\footnotetext{
${ }^{26}$ We rescale $P_{t}^{G}$ so that it is equal to $P_{t}$ in the year prior to the crisis.
} 
to trend real GDP to capture the fact that transfers are not very cyclically sensitive in industrializing countries. Our specification also captures a key feature of our theoretical model: some transfers are sensitive to changes in relative prices, while others are not. Since we do not have any data that distinguishes between these two types of transfers, we use the following procedure to estimate $\psi$ and $\bar{\psi}$. We assume that $\epsilon_{t}^{v}$ is uncorrelated with $\bar{S}_{t} / S_{t}$ and estimate $\bar{\psi}$ and $\psi$ by regressing $v_{t} /\left(\bar{p}_{t} \bar{Y}_{t}\right)$ on a constant and $\bar{S}_{t} / S_{t}$. Using Korean data for the period 1980-97 we obtained $\psi=0.0415$ and $\bar{\psi}=0.0007$.

We assume that, in the absence of the crisis, expected total transfers (measured in dollars) are $v_{t}^{e}=(\bar{\psi}+\psi) p_{t}^{e} Y_{t}^{e}$. The total change in transfer spending due to the crisis is:

$$
\Delta(v)=\sum_{t=t_{a}+1}^{T_{a}}(1+r)^{-\left(t-t_{a}\right)}\left(v_{t}-v_{t}^{e}\right) .
$$

We decompose $\Delta(v)$ into two components: (i) a relative price effect; and (ii) a residual effect that we ascribe to explicit fiscal reform. We define the change in transfers due to changes in relative prices as:

$$
\Delta(v, p)=\sum_{t=t_{a}+1}^{T_{a}}(1+r)^{-\left(t-t_{a}\right)} \psi\left(S_{t}^{e} / S_{t}-1\right) p_{t}^{e} Y_{t}^{e}
$$

Here $S_{t}^{e}$ is set equal to the projection implied by a log-linear trend fit to $S_{t}$ over the period 1980-97. This projection and the implied projection $P_{t}^{e}=p_{t}^{e} S_{t}^{e}$ are illustrated in Figures $3(\mathrm{c})$ and $3(\mathrm{~d})$.

The residual component, or explicit change in transfers, is:

$$
\Delta(v, e)=\Delta(v)-\Delta(v, p)
$$

Figure 4(e) illustrates the actual path of government transfers in Korea, along with the trend path implied by our calculations. We estimate that through 2001, the Korean government saved 30.0 billion dollars on its transfers as a result of the crisis, most of which (35.6 billion dollars) was due to the change in relative prices.

Korea Case Study: Summary In summary, our results for Korea are as follows. The fiscal cost of the banking sector bailout was approximately 114.4 billion dollars or 24.0 percent of Korea's GDP in 1997. Lost revenue due to the post-crisis recession was roughly 48.7 billion dollars or 10.2 percent of GDP. Explicit fiscal reforms amounted to 56.9 billion dollars or 
11.9 percent of GDP. Taken together these results imply that the Korean government had to raise 106.1 billion dollars or 22.3 percent of GDP, to pay for the remaining fiscal costs.

Table 7 summarizes our estimate of how much has been financed until now. To date the government has raised 42.9 billion dollars (9.6 percent of GDP) of the costs associated with the crisis. Most of these resources were raised through a substantial decline in the dollar value of transfers amounting to 7.5 percent of GDP. Offsetting this was the decline in government revenue net of government purchases of goods and services, which amounted to -3.1 percent of GDP. Because the Korean government had only modest amounts of won-denominated debt, only 3.5 percent of GDP was raised by deflating its dollar value. Additional seigniorage contributed only 1.7 percent of GDP in new revenue. So total depreciation-related revenue so far adds up to about 9.6 percent of GDP. Given our estimates, the government must still pay for 57.1 percent of the fiscal cost, or 12.7 percent of pre-crisis GDP. Our model can account for the large depreciation and modest post-crisis inflation rates in Korea under the assumption that much of the remaining fiscal cost of the crisis will be financed through future explicit fiscal reforms, and implicit declines in the dollar value of transfers.

We conclude by emphasizing that, in both the data and our model, seigniorage, the source of financing most emphasized in the literature, plays a relatively minor role. In reality the two most important sources of financing are large reductions in both the dollar value of government purchases and transfer payments.

\subsection{Case study: Mexico}

Timing and Interest Rates For Mexico the month and year in which the crisis occurred, $t_{m}$ and $t_{a}$, are given by November 1994 and 1994, respectively. So we measure seigniorage and debt deflation beginning with December 1994, and changes in government revenue, purchases, and transfers beginning in 1995. We set the annual dollar interest rate to $r=0.109$. This corresponds to the average EMBI (Mexico) dollar spread plus the US 3-month T-bill rate between December 1994 and January 2003.

Seigniorage Revenue We measured actual seigniorage revenue $\left(M_{t}-M_{t-1}\right) / S_{t}$ using the same method as in the Korean case. As above we assumed that, in the absence of a crisis, the money stock would have been $M_{t}^{e}=M_{t_{m}}\left(1+\mu_{m}\right)^{t-t_{m}}$ and the exchange rate would have been $S_{t}^{e}=S_{t_{m}}\left(1+\delta_{m}\right)^{t-t_{m}}$. We set $\mu_{m}=0.0114$ and $\delta_{m}=0.003$, which are the average monthly rates of money growth and depreciation between June 1991 and June 1994. The 
last period for which we have monthly money stock data for Mexico $\left(T_{m}\right)$ is November 2002.

According to our estimates, the increase in the Mexican government's seigniorage revenue between December $1994\left(t_{m}+1\right)$ and November $2002\left(T_{m}\right)$ was 6.7 billion dollars, or 1.7 percent of Mexico's GDP in 1994.

Debt Deflation Our data on Mexico's outstanding domestic debt is summarized in Table 6 , which indicates the quantities of two types of bonds outstanding (net of central bank holdings) at the end of November 1994 along with information on their maturities. Cetes are peso denominated bonds similar to T-bills and Ajustabonos are bonds indexed to the CPI. Mexico also issued domestic securities called Tesabonos and Bondes prior to the crisis. However, Tesabonos were indexed to the dollar and Bondes had adjustable interest rates. For this reason we ignore these securities in our calculations. For each type of bond, we assume that equal quantities of each maturity were outstanding in November 1994. As for Korea, within each maturity we assume that there are equal numbers of bonds within 1 month of their maturity date as there are within 2 months, 3 months, etc., of their maturity date. We also treat all bonds as if they were zero coupon bonds.

All Cetes and Ajustabonos outstanding at the end of November 1994 would have been paid back by $T_{b}=$ November 1999 . So, for Cetes we measure debt deflation as:

$$
\text { Debt deflation }=\sum_{t=t_{m}+1}^{T_{b}}\left(1+r_{m}\right)^{-\left(t-t_{m}\right)} B_{t}^{C}\left(\frac{1}{S_{t}^{e}}-\frac{1}{S_{t}}\right) .
$$

Here $B_{t}^{C}$ represents the number of Cetes maturing at date $t$. For Ajustabonos we measure debt deflation as:

$$
\text { Debt deflation }=\sum_{t=t_{m}+1}^{T_{b}}\left(1+r_{m}\right)^{-\left(t-t_{m}\right)} \frac{B_{t}^{A}}{P_{t_{m}}}\left(\frac{P_{t}^{e}}{S_{t}^{e}}-\frac{P_{t}}{S_{t}}\right) .
$$

Here $B_{t}^{A}$ represents the number of Ajustabonos maturing at date $t, P_{t}$ represents the CPI, and $P_{t}^{e}=P_{t_{m}}\left(1+\pi_{m}\right)^{t-t_{m}}$ is an estimate of what the CPI would have been in the absence of the crisis. We set $\pi_{m}=0.0086$, the average monthly CPI inflation rate between June 1991 and June 1994.

For Mexico, the total value of all outstanding Cetes and Ajustabonos at the end of November 1994 was roughly 71.7 billion pesos, or 5.1 percent of 1994 GDP. We estimate that revenue from debt deflation was about 6.9 billion dollars or 1.7 percent of GDP. Figure 5 illustrates the time series of Mexico's revenue from debt deflation from 1994 through 1999. 
As in the Korean case, much of the revenue from debt deflation accrued in the first six months after the crisis.

Changes in Tax Revenues To measure the change in taxes due to the crisis, we use the same method as in the Korean case. Our Mexican data set spans the period 1980-2002. Over this period, the Mexican economy experienced substantially more volatility than the Korean economy. For this reason, we used Hodrick-Prescott trends rather than simple linear trends to construct the $\bar{p}_{t}$ and $\bar{Y}_{t}$ series used in the estimation of $\tau^{L}$. Using data for the period 1980-2002 we estimate $\tau^{L}=0.015$. We chose $\tau=0.213$ so that the implied ratio of taxes to GDP along the trend path would be equal to 0.228 , the ratio of taxes to GDP in $1994 .^{27}$

To project tax revenue beyond the crisis we set $T_{t}^{e}=\left(\tau^{L}+\tau\right) p_{t}^{e} Y_{t}^{e}$. We computed the projections $p_{t}^{e}$ and $Y_{t}^{e}$ by assuming that $p_{t}$ and $Y_{t}$ were expected to increase by 6.6 and 3.3 percent per year, respectively, from their 1994 values. These growth rates correspond to the average growth rates of $p_{t}$ and $Y_{t}$ in the period 1991-94. These projections are illustrated in Figures 6(a) and 6(b). Given the values of $\tau^{L}$ and $\tau$, and the series $T_{t}, p_{t}$, and $Y_{t}$, we compute the change in tax revenue due to the crisis - and its decomposition into output, relative price, and explicit reform components - as we did for Korea.

Figure 7 (a) illustrates the actual path of government revenue in Mexico along with the trend path implied by our calculations. We estimate that through 2001 Mexican tax revenues fell by 216.3 billion dollars as a result of the crisis. Of this total, 25.9 billion dollars were due to output losses and 159.8 billion dollars were due to the change in relative prices. In addition, we estimate that there were explicit tax cuts amounting to about 30.5 billion dollars.

Changes in Government Purchases of Goods and Services We set the trend share of government purchases to GDP, $g$, equal to the ratio of government purchases to GDP in 1994, 0.143. We then decomposed the change in government purchases into a relative price effect and explicit fiscal reform using the same method as for Korea. Figure 7(c) illustrates the actual path of government purchases in Mexico along with the projected path, $G_{t}^{e}$, implied by our calculations. We estimate that through 2001 the Mexican government saved 173.8

\footnotetext{
${ }^{27}$ If we estimate $\tau$ with the same procedure used to estimate $\tau^{L}$, we find $\tau=0.231$. This value of $\tau$, along with our estimate of $\tau^{L}$,implies a ratio of taxes to GDP along the trend path equal to 0.246 . This ratio is considerably higher than the actual ratio of taxes to GDP in the years 1991-94.
} 
billion dollars on its purchases as a result of the crisis. Of this total, 102.4 billion dollars were due to the change in relative prices, while 71.3 billion dollars were due to explicit cuts in spending.

Changes in Spending on Transfers For $S_{t}^{e}$, we assumed that the exchange rate was projected to rise at 3.8 percent per year, which was the peso's average depreciation rate in the period 1991-94. The path for $S_{t}^{e}$ and the implied path for $P_{t}^{e}$ (given by $P_{t}^{e}=p_{t}^{e} S_{t}^{e}$ ) are displayed in Figures 6(c) and 6(d).

Our estimate of $\bar{\psi}$, obtained using data for the period $1980-2002$, is 0.003 . The value of $\psi$ was chosen so that the trend value of transfers to GDP coincides with the actual value of the ratio of transfers to GDP in 1994 (6.2 percent). This yields a value of $\psi$ equal to 0.0614. Figure 7(e) illustrates the actual path of government transfers in Mexico along with the trend path implied by our calculations.

We estimate that through 2001 the Mexican government saved 43.2 billion dollars on its transfers as a result of the crisis through a combination of 93.9 billion dollars due to changes in relative prices and explicit fiscal reforms of -50.8 billion dollars (i.e., there were explicit increases in transfers in Mexico).

Mexico Case Study: Summary In summary, our results for Mexico are as follows. The fiscal cost of the banking sector bailout was approximately 60.1 billion dollars or 15.0 percent of Mexico's GDP in 1994. Lost revenue due to the post-crisis recession was roughly 25.9 billion dollars or 6.5 percent of GDP. Explicit fiscal reforms amounted to -10.0 billion dollars or -2.5 percent of GDP. Taken together these results imply that the Mexican government had to raise 96.0 billion dollars, or 23.9 percent of GDP, of depreciation-related revenues.

To date, the government has raised 52.2 percent (12.5 percent of GDP) of the costs associated with the crisis, as summarized in Table 7. Most of these resources were raised through a substantial decline in the dollar value of transfers amounting to 23.4 percent of GDP, but these were offset by a substantial decline in the dollar value of government revenue net of government purchases of goods and services: -14.3 percent of GDP. Because the Mexican government had only modest amounts of peso-denominated debt, only 1.7 percent of GDP was raised by deflating its dollar value. Additional seigniorage contributed 1.7 percent of GDP in new revenue. Given our estimates, the government must still pay for the remaining 47.8 percent of the fiscal costs (11.4 percent of pre-crisis GDP). 
Absent any indication of large impending fiscal reforms, it seems reasonable to suppose that much of the remainder of the fiscal costs will be paid for with seigniorage revenues. We estimate that if, from November 2002 on, the monetary base grew at the same monthly rate as under the counterfactual, $\mu_{m}=0.0114$, and the peso depreciated at the same rate as under the counterfactual, the government would raise 12.5 percent of pre-crisis GDP from additional seigniorage. This would be slightly more revenue than the government would need to fully finance the remaining costs associated with the crisis. Of course, if Mexico prints money more quickly or the peso depreciates less slowly than under our assumptions, then the government will be able to cover the fiscal costs of the crisis more quickly.

The key point is that, absent any sign of explicit fiscal reforms, it seems quite likely that the bulk of the costs will be covered via explicit seigniorage revenues. Our model would predict that with this much financing coming from seigniorage, the rate of inflation in Mexico would be considerably higher than it would have been had the implicit fiscal reforms or the initial domestic debt been larger.

\subsection{Case study: Turkey}

Timing and Interest Rates For Turkey, the month and year prior to the occurrence of the crisis, $t_{m}$ and $t_{a}$, are given by January 2001 and 2000, respectively. So we measure seigniorage and debt deflation beginning with February 2001 and changes in government revenue, purchases, and transfers beginning in 2001. We set the annual dollar interest rate to $r=0.1066$. This corresponds to the average EMBI+ (Turkey) dollar spread plus the US 3-month T-bill rate between February 2001 and January $2003 .^{28}$

Seigniorage Revenue We measured actual seigniorage revenue $\left(M_{t}-M_{t-1}\right) / S_{t}$ using the same method as in the Korean case. As above we assumed that, in the absence of a crisis, the money stock would have been $M_{t}^{e}=M_{t_{m}}\left(1+\mu_{m}\right)^{t-t_{m}}$ and the exchange rate would have been $S_{t}^{e}=S_{t_{m}}\left(1+\delta_{m}\right)^{t-t_{m}}$. We set $\mu_{m}=0.0238$ and $\delta_{m}=0.0175$, which are the average monthly rates of money growth and depreciation between January 2000 and January 2001. The last period for which we have monthly money stock data for Turkey $\left(T_{m}\right)$ is October 2002.

According to our estimates, the increase in the Turkish government's seigniorage revenue

\footnotetext{
${ }^{28}$ Between the inception of the EMBI+ for Turkey in August 1999 and the end of January 2001 this rate averaged 10.63 percent.
} 
between February $2001\left(t_{m}+1\right)$ and October $2002\left(T_{m}\right)$ was 3.7 billion dollars, or 1.8 percent of Turkey's GDP in 2000.

Debt Deflation Table 6 summarizes our data on Turkey's outstanding securitized domestic debt. This table indicates the quantities and maturity of different types of bonds outstanding at the end of January 2001. Turkey had only very small amounts of indexed domestic debt, from which we abstract.

We assume that for each type of bond there were equal quantities outstanding in each month beginning in February 2001 and ending at the month corresponding to twice the average maturity date given in Table 6 . We treat all bonds as if they were zero coupon bonds.

We use the same expression for debt deflation that we used for Korea. In this case, all government debt outstanding at the end of January 2001 should be paid back by $T_{b}=$ April 2009. The last date for which we have data on $S_{t}$, denoted $T_{s}$, is equal to December 2002.

For Turkey, the total value of all domestic debt not held by the public sector at the end of January 2001 was roughly 35.5 quadrillion Turkish lire, or 28.5 percent of 2000 GDP. We estimate that revenue from debt deflation was about 14.6 billion dollars or 7.3 percent of GDP. Figure 8 illustrates the time series of Turkey's revenue from debt deflation from 2001 projected out to 2009. As in the Korean and Mexican cases, much of the revenue from debt deflation accrued in the first year after the crisis. Notice, however, that the amount of revenue raised by debt deflation is much larger in the Turkish case.

Changes in Tax Revenues To project tax revenue beyond the crisis we used a simpler model than for Korea and Mexico. We set $T_{t}^{e}=\tau p_{t}^{e} Y_{t}^{e}$ and set $\tau=0.271$, the ratio of taxes to GDP in 2000. Since $p_{t}$ had been relatively stable in Turkey for many years we assume that agents expected it to remain constant at its value in 2000 . We set the annual growth rate of $Y_{t}^{e}$ to 3.7 percent. This corresponds to the average growth rate of $Y_{t}$ in the period 1987-2000. These projections are illustrated in Figures 9(a) and 9(b). Given the value of $\tau$ and the series $T_{t}, p_{t}$, and $Y_{t}$, we compute the change in tax revenue due to the crisis and its decomposition into output, relative price, and explicit components as we did for Korea.

Figure 10(a) illustrates the actual path of government revenue in Turkey along with the trend path implied by our calculations. We estimate that through 2002 Turkish tax revenues fell by 19.3 billion dollars as a result of the crisis. Of this total, 8.7 billion dollars were due 
to output losses and 14.2 billion dollars were due to the change in relative prices. In addition we estimate that there were explicit tax increases amounting to about 3.6 billion dollars.

Changes in Government Purchases of Goods and Services We set the trend share of government purchases to GDP, $g$, equal to 0.201, which is the ratio of government purchases to GDP in 2000. We then decomposed the change in government purchases into a relative price effect and explicit fiscal reform using the same method as for Korea. Figure 10(c) illustrates the actual path of government purchases in Turkey along with the projected path, $G_{t}^{e}$, implied by our calculations. We estimate that through 2002 the Turkish government saved 15.3 billion dollars on its purchases as a result of the crisis. Of this total, 6.0 billion dollars were due to the change in relative prices, while 9.3 billion dollars were due to explicit cuts in spending.

Changes in Spending on Transfers For $S_{t}^{e}$, we assumed that the exchange rate was projected to rise at 21.2 percent per year, which was the Turkish Lira's depreciation rate in the period January 2000-January 2001. The path for $S_{t}^{e}$ and the implied path for $P_{t}^{e}$ (given by $P_{t}^{e}=p_{t}^{e} S_{t}^{e}$ ) are displayed in Figures $9(\mathrm{c})$ and $9(\mathrm{~d})$.

We set $\bar{\psi}=0$ and $\psi=0.074$ so that the trend value of transfers to GDP coincides with the actual value of the ratio of transfers to GDP in 2000 (7.4 percent). Figure 10(e) illustrates the actual path of government transfers in Turkey along with the trend path implied by our calculations.

We estimate that, through 2002, the Turkish government enacted explicit increases in transfers worth 6.3 billion dollars. At the same time, the government benefited from an automatic reduction in the dollar value of transfers due to changes in relative prices worth 10.5 billion dollars. The net result was a reduction in the value of transfers of 4.3 billion dollars.

Turkey Case Study: Summary In summary, our results for Turkey are as follows. The fiscal cost of the banking sector bailout was approximately 36.2 billion dollars or 18.2 percent of Turkey's GDP in 2000. Lost revenue due to the post-crisis recession was roughly 8.7 billion dollars or 4.4 percent of GDP. Explicit fiscal reforms amounted to 6.7 billion dollars or 3.3 percent of GDP. Taken together these results imply that the Turkish government had to raise 38.3 billion dollars, or 19.2 percent of GDP, of depreciation-related revenues. 
To date we estimate that the government has raised 53.8 percent (10.3 percent of GDP) of the costs associated with the crisis, as summarized in Table 7. Most of these resources were raised through a substantial decline in the dollar value of Turkey's domestic debt amounting to 7.3 percent of GDP and through increased seigniorage revenues (1.8 percent of GDP). The dollar value of transfers declined by 5.3 percent of GDP, but these were offset by a decline in the dollar value of government revenue net of government purchases of goods and services of -4.1 percent of GDP. Based on this evidence we conclude that the Turkish case is quite different than the Korean and Mexican cases. First, while all three countries have so far financed about 50 percent of the net fiscal costs associated with their crises, Turkey has done so much more quickly (2 years for Turkey versus 5 and 8, respectively for Korea and Mexico). Second, the Turkish government has relied much more on seigniorage and debt deflation, while the Korean and Mexican governments have relied more on implicit fiscal reform.

\section{Conclusion}

This paper explored the implications of different strategies for financing the fiscal costs associated with a currency crisis for inflation and depreciation rates. We argue that models based on the assumption that seigniorage is the only depreciation-related source of revenue lead to misleading predictions about post-crisis rates of inflation and depreciation. We then show that models that incorporate an empirically plausible menu of depreciation-related revenues can account for the high depreciation rates and low inflation rates that are often observed in the aftermath of currency crises.

Our case studies indicate that different governments pursue different financing strategies. For example, debt deflation played a more important role in Turkey than in Korea or Mexico. In contrast, the reduction in the dollar value transfers played a very large role in Mexico. This paper is silent on why these governments chose different strategies. In our view, understanding the political economy considerations that underlie these choices is an important topic for future research. 
TABLE 1

SEIGNIORAGE

(Average of 2 Years Before and After Each Country's Crisis, \% of GDP)

\begin{tabular}{lcc}
\hline \hline Country & $\begin{array}{c}\text { Before } \\
\text { Crisis }\end{array}$ & $\begin{array}{c}\text { After } \\
\text { Crisis }\end{array}$ \\
\hline Korea & 0.1 & 0.6 \\
Thailand & 1.5 & 2.7 \\
Philippines & 2.7 & 2.1 \\
Mexico & 0.4 & 0.9 \\
Brazil & 0.6 & 0.7 \\
Turkey & 3.5 & $2.8^{*}$ \\
\hline
\end{tabular}

${ }^{*}$ Estimate based on data through Oct. 2002. 
TABLE 2

Inflation and Depreciation Rates

(percent)

\begin{tabular}{|c|c|c|c|}
\hline \multicolumn{2}{|l|}{ Country } & $\begin{array}{c}\text { Cumulative } \\
\text { Exchange Rate }\end{array}$ & $\begin{array}{l}\text { Cumulative } \\
\text { CPI }\end{array}$ \\
\hline \multirow[t]{2}{*}{ Korea } & Sep. 97-Sep. 98 & 50.9 & 6.9 \\
\hline & —Sep. 99 & 31.8 & 7.7 \\
\hline \multirow[t]{2}{*}{ Thailand } & June 97 - June 98 & 67.1 & 15.5 \\
\hline & —June 99 & 45.4 & 14.2 \\
\hline \multirow{2}{*}{ Philippines } & June 97 - June 98 & 54.2 & 17.0 \\
\hline & —June 99 & 44.7 & 23.7 \\
\hline \multirow[t]{2}{*}{ Mexico } & Nov. 94 -Nov. 95 & 94.8 & 47.2 \\
\hline & -Nov. 96 & 101.5 & 88.0 \\
\hline \multirow[t]{2}{*}{ Brazil } & Dec. 98 -Dec. 99 & 52.9 & 8.9 \\
\hline & 一Dec. 00 & 62.9 & 15.5 \\
\hline \multirow[t]{2}{*}{ Turkey } & Jan. 01-Jan. 02 & 103.2 & 73.2 \\
\hline & 一Dec. 02 & 144.3 & 118.8 \\
\hline
\end{tabular}

Notes: The rate of depreciation is calculated as $100\left(S_{t+j} / S_{t}-1\right)$, where $S_{t}$ is the monthly average exchange rate. 
TABLE 3

Change in the Relative Price of Nontradables (percent)

\begin{tabular}{lcc}
\hline \hline Country & & $\begin{array}{c}\text { Change in Dollar } \\
\text { Price of } \\
\text { Nontradables }\end{array}$ \\
\hline Korea & Sep. 97-Sep. 98 & -30.3 \\
Thailand & June 97-June 98 & -33.2 \\
Philippines & June 97-June 98 & -27.7 \\
Mexico & Nov. 94-Nov. 95 & -38.4 \\
Brazil & Dec. 98-Dec. 99 & -30.0 \\
Turkey & Jan. 01-Jan. 02 & -18.9 \\
\hline
\end{tabular}


TABLE 4

Model Parameters

\begin{tabular}{ll}
\hline (a) Benchmark case & \\
\hline$\sigma=1$ & inverse of elasticity of intertemporal substitution \\
$\omega=0.5$ & share of tradables in CPI \\
$r=0.055$ & real interest rate \\
$S=1$ & initial exchange rate \\
$y^{T}=1$ & output of tradables \\
$y^{N}=1$ & output of nontradables \\
$p^{N}=1.86$ & initial relative price of nontradables \\
$y=y^{T}+p^{N} y^{N}=2.86$ & initial GDP (in dollars) \\
$g=0.153 y$ & initial government purchases (in dollars) \\
$g^{T}=0.132 g$ & initial government purchases of tradables \\
$g^{N}=\left(g-g^{T}\right) / p^{N}$ & initial government purchases of nontradables \\
$v=0.043 y$ & initial total transfers (in dollars) \\
$v^{*}=0$ & initial transfers to foreigners (in dollars) \\
$P \hat{v} / S=0.027 y$ & initial CPI-indexed transfers (in dollars) \\
$(M / S) / y=0.067$ & initial ratio of base money to GDP \\
$\tau^{T}=\tau^{N}=0.213$ & tax rates on tradable and nontradable goods \\
$b_{0}=-0.057 y$ & initial government dollar debt level \\
$B=0.075 y$ & government nominal debt \\
$\phi=0.135$ & amount financed by devaluation-based revenues \\
$t^{*}=0.33$ & time of the speculative attack \\
$T=0.5$ & time of switch to new monetary policy \\
$M_{T} / M=1.12$ & ratio of base money at time $T$ to initial base money \\
$\delta=0.5$ & distribution cost of tradables \\
\hline (b) Without nominal debt: same as (a) except $B=0$ \\
(c) Without CPI-indexed transfers: same as (a) except $\hat{v}=0$ \\
(d) Without nominal debt and CPI-indexed transfers: same as (a) except $B=\hat{v}=0$ \\
(e) Basic textbook model: same as (a) except $\omega=1, y^{N}=g^{N}=\hat{v}=B=\delta=0$, \\
$\begin{array}{ll}\text { (f) } \ldots \text { adding nominal debt: same as (e) except } B=0.075 y \\
\text { (g) } \ldots \text { adding nontraded goods with sticky prices: same as (a) except } \delta=0 \text { and } \hat{v}=0 \\
\text { (h) } \ldots \text { adding CPI-indexed transfers: same as (a) except } \delta=0\end{array}$ \\
\hline
\end{tabular}

Note: The alternative models are described in the text. The letters and cases correspond to those in Table 5. 
TABLE 5

Korea Calibration, Numerical Results

\begin{tabular}{|c|c|c|c|c|c|c|c|}
\hline \multirow[b]{4}{*}{ a) Benchmark model } & \multicolumn{2}{|c|}{ Inflation } & \multirow{3}{*}{$\begin{array}{c}\text { Deprec. } \\
\text { Yr } 1\end{array}$} & \multicolumn{4}{|c|}{ Financing (percent of GDP) } \\
\hline & \multirow[t]{2}{*}{ Yr 1} & \multirow[t]{2}{*}{ Long-run } & & \multirow[t]{2}{*}{ Seig. } & \multirow{2}{*}{$\begin{array}{c}\text { Nominal } \\
\text { Debt } \\
\text { Deflation }\end{array}$} & \multicolumn{2}{|c|}{$\begin{array}{c}\text { Implicit } \\
\text { Fiscal Reforms }\end{array}$} \\
\hline & & & & & & $g-\tau$ & Transfers \\
\hline & 12.7 & 2.0 & 46.5 & 2.0 & 3.6 & -3.1 & 11.1 \\
\hline \multicolumn{8}{|l|}{ Alternative Financing Scenarios } \\
\hline b) Benchmark without nominal debt & 16.4 & 6.0 & 51.7 & 5.5 & 0 & -3.1 & 11.2 \\
\hline c) Benchmark without CPI-indexed transfers & 22.5 & 12.7 & 60.3 & 11.0 & 5.7 & -3.2 & 0 \\
\hline d) Benchmark without both & 29.2 & 20.1 & 69.9 & 16.7 & 0 & -3.2 & 0 \\
\hline \multicolumn{8}{|l|}{ Deconstructing the Model } \\
\hline e) Simple textbook model & 23.3 & 11.5 & 23.3 & 13.5 & 0 & 0 & 0 \\
\hline f) Textbook model adding nominal debt & 19.6 & 7.3 & 19.6 & 9.1 & 4.4 & 0 & 0 \\
\hline g) Case (f) adding nontraded goods with sticky prices & 20.3 & 9.7 & 34.2 & 10.4 & 5.1 & -2.0 & 0 \\
\hline h) Case (g) adding CPI-indexed transfers & 16.4 & 5.4 & 29.7 & 6.2 & 4.3 & -2.0 & 4.9 \\
\hline Empirical Estimates & $7.2^{*}$ & $2.5^{\dagger}$ & $45.0^{*}$ & $1.8^{\ddagger}$ & $3.5^{\ddagger}$ & $-3.1^{\ddagger}$ & $7.5^{\ddagger}$ \\
\hline
\end{tabular}

*Oct. 1997-Oct. 1998.

${ }^{\dagger}$ Average rate between Nov. 1998 and Aug. 2002.

${ }^{\ddagger}$ Seigniorage is measured monthly through Sep. 2002. Debt deflation is measured monthly through Nov. 2002, and includes an estimate of future debt deflation. The implicit fiscal reforms are measured annually through 2001. 
TABLE 6

Outstanding Domestic Debt

\begin{tabular}{|c|c|c|c|}
\hline & $\begin{array}{c}\text { Value } \\
\text { Outstanding } \\
\end{array}$ & Maturities & $\begin{array}{c}\text { Average Mos. } \\
\text { to Maturity }\end{array}$ \\
\hline (a) Korea, End of October 1997 & (trillion won) & & \\
\hline Grain securities & 4.9 & 1,3 and 5 yrs. & n.a. \\
\hline Subway construction bond & 3.0 & 3 yrs. & n.a. \\
\hline National housing bond & 12.7 & $5-10$ yrs. & n.a. \\
\hline FX stabilization fund bonds & 4.0 & $1-5$ yrs. & n.a. \\
\hline Treasury bonds & 5.8 & $1-10$ yrs. & n.a. \\
\hline Monetary stabilization bonds & 26.4 & $\begin{array}{l}0.5,1,2,3,4.5 \\
6,12,18 \text { mos. }\end{array}$ & n.a. \\
\hline Industrial finance debentures & 17.1 & $1-10$ yrs. & n.a. \\
\hline (b) Mexico, End of September 1994 & (billion pesos) & & \\
\hline Cetes & 42.2 & $1,3,6$ and 12 mos. & n.a. \\
\hline Ajustabonos & 29.5 & 3 and 5 yrs. & n.a. \\
\hline (c) Turkey, End of January 2001 & (quadrillion TL) & & \\
\hline \multirow[t]{5}{*}{ Government Bonds (cash) } & 0.7 & $1 \mathrm{Yr}$. & 5.9 \\
\hline & 14.7 & Irregular $1-2$ Yrs & 7.0 \\
\hline & 2.9 & 2 Yrs. & 11.7 \\
\hline & 2.0 & Irregular $2-3$ Yrs. & 18.3 \\
\hline & 1.1 & 3 Yrs. & 18.3 \\
\hline Government Bonds (noncash) & 11.4 & & 50.0 \\
\hline \multirow[t]{5}{*}{ Treasury Bills (cash) } & 0.8 & 3 Mos. & 1.6 \\
\hline & 0.1 & Irregular 3- 6 Mos. & 3.7 \\
\hline & 0.9 & 6 Months & 5.4 \\
\hline & 0.1 & Irregular $6-9$ Mos. & 5.6 \\
\hline & 0.9 & Irregular $9-12$ Mos. & 4.9 \\
\hline Treasury Bills (noncash) & 0.0 & & 1.0 \\
\hline
\end{tabular}

Sources: See Data Appendix. 
TABLE 7

New Sources of Government Finance

\begin{tabular}{lcc}
\hline \hline & \% of GDP & \% of Total Cost \\
\hline \multicolumn{2}{c}{ (a) Korea } & \\
& & \\
Seigniorage & 1.7 & 7.6 \\
Debt deflation & 3.5 & 15.7 \\
Implicit decline in transfers & 7.5 & 33.6 \\
Implicit decline in purchases-taxes & -3.1 & -13.9 \\
TOTAL FINANCING TO DATE & 9.6 & 42.9 \\
\hline & & \\
\multicolumn{2}{c}{ (b) Mexico } & \\
& 1.7 & 7.0 \\
Seigniorage & 1.7 & 7.2 \\
Debt deflation & 23.4 & 97.9 \\
Implicit decline in transfers & -14.3 & -59.8 \\
Implicit decline in purchases-taxes & 12.5 & 52.2 \\
TOTAL FINANCING TO DATE & & \\
\hline & & \\
(c) Turkey & & \\
Seigniorage & 1.8 & 9.6 \\
Debt deflation & 7.3 & 38.2 \\
Implicit decline in transfers & 5.3 & 27.5 \\
Implicit decline in purchases-taxes & -4.1 & -21.6 \\
TOTAL FINANCING TO DATE & 10.3 & 53.8 \\
\hline
\end{tabular}




\section{FIGURE 1}

EQUILIBRIUM PATHS IMPLIED BY THE MODEL

(a) Benchmark Model
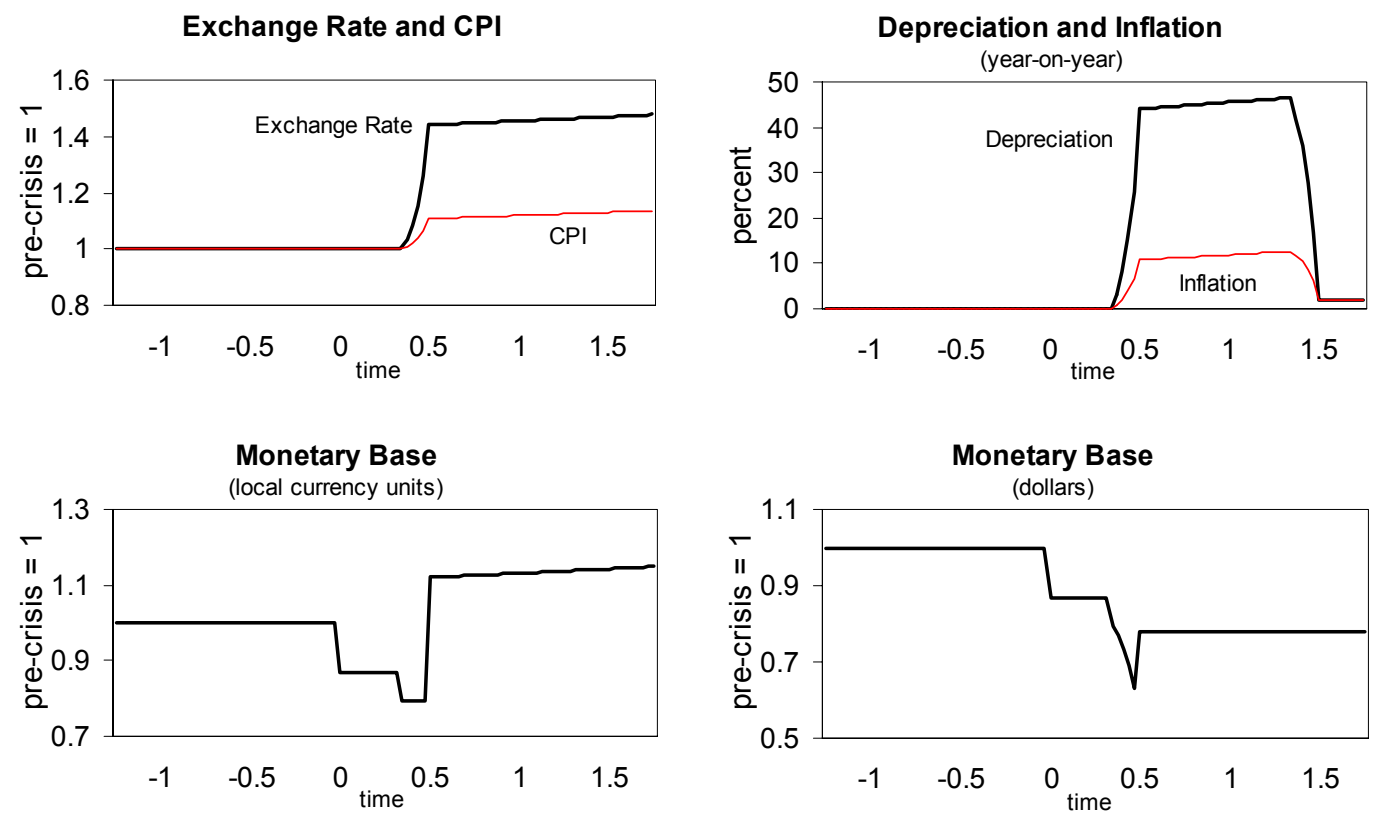

(b) Basic Textbook Model
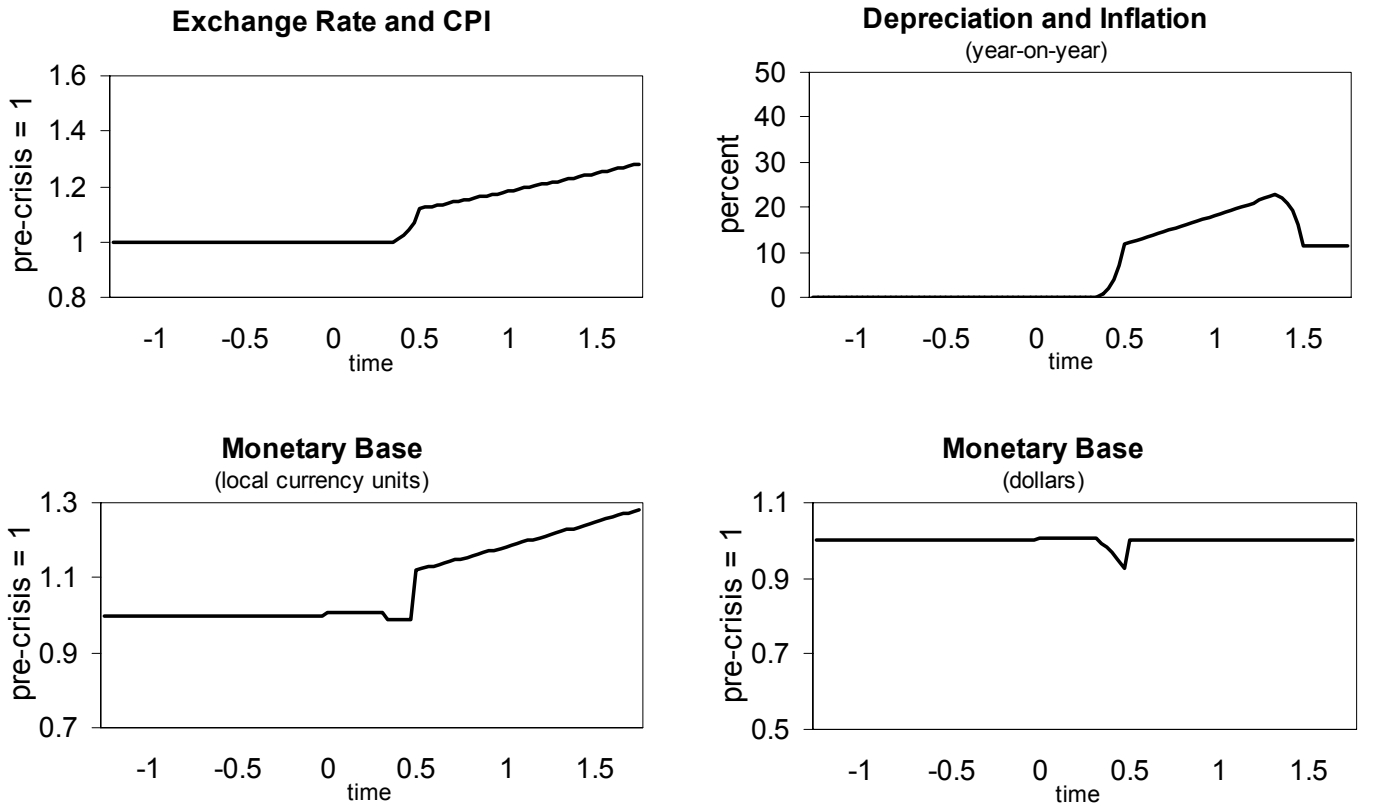

Note: The benchmark model (a) is our full model with nontradable goods, distribution costs, sticky prices, nominal debt, and CPI-indexed transfers. The basic textbook model (b) has none of these features. 
FIGURE 2

REVEnUE From DeBt DeFLATIOn IN KoREA, 1997-2007

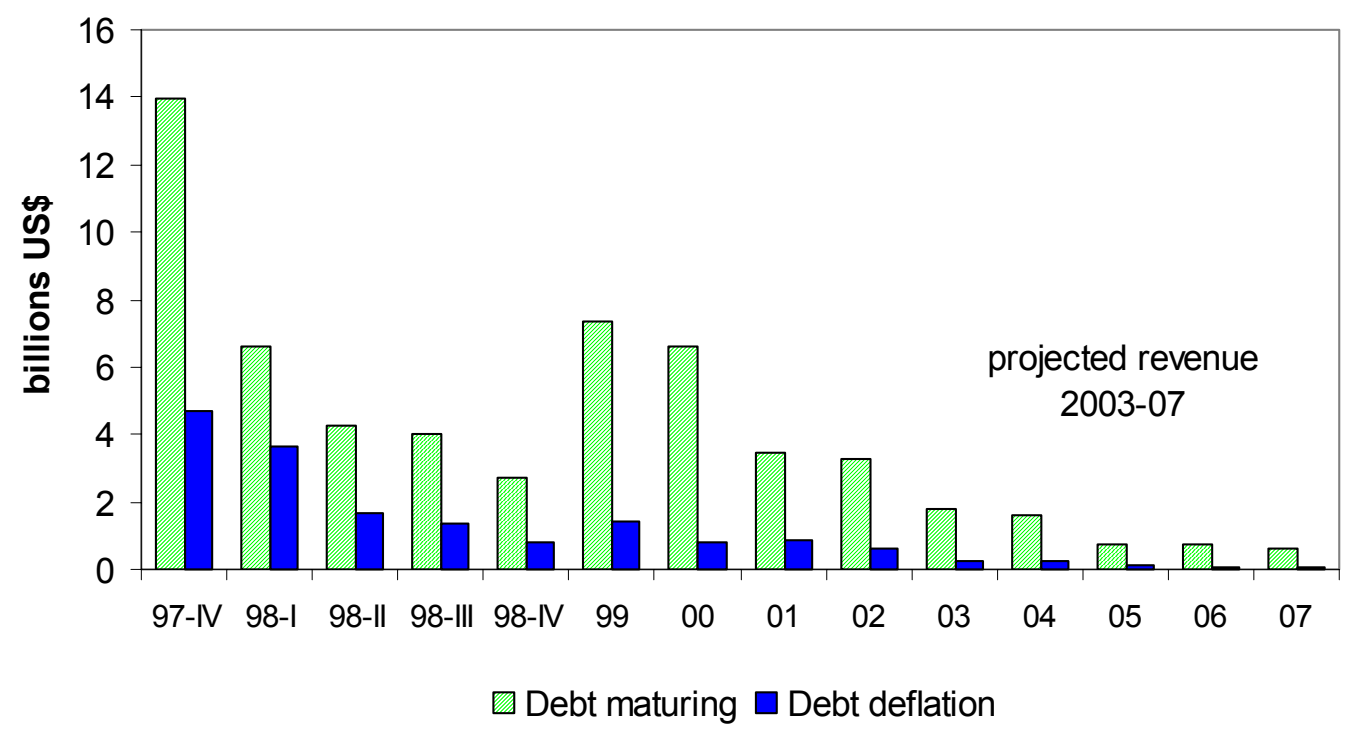

Notes: The quantity of debt maturing is sum of the face values (in won) of all debt maturing within each time period divided by the exchange rate (won/dollar). Debt deflation is unanticipated revenue from the decline in the dollar value of domestic debt. See the text for the details of the calculations and data. 


\section{FIGURE 3}

Estimated TREND PATHS FOR KOREAN TIME SERIES

(a) Real GDP (Y)

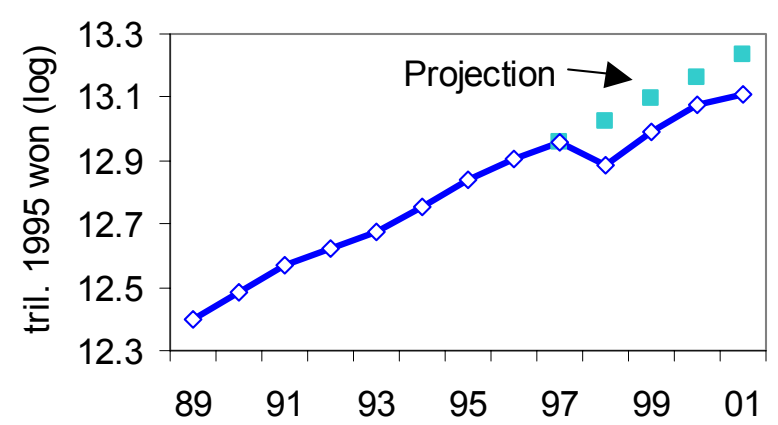

(c) Exchange Rate (S)

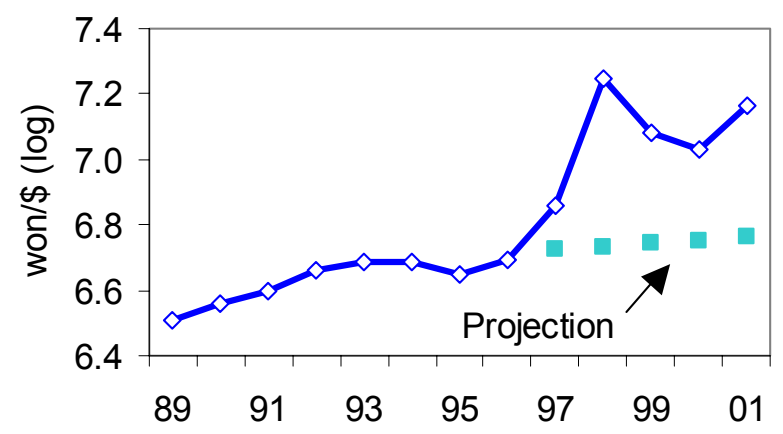

(b) GDP Deflator / Exch. Rate (p)

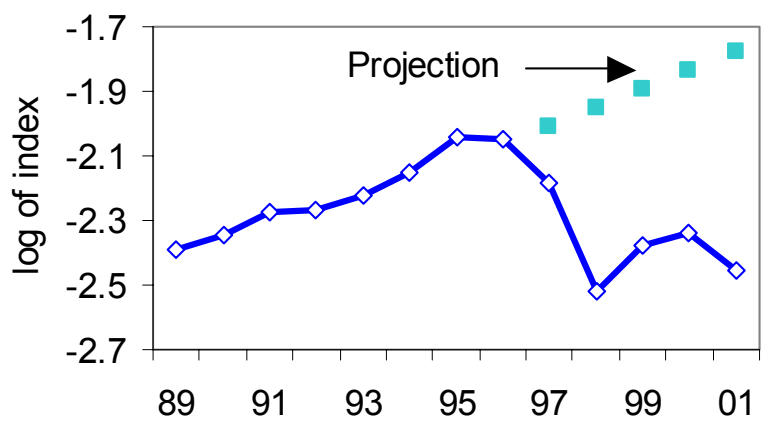

(d) GDP Deflator $(P)$

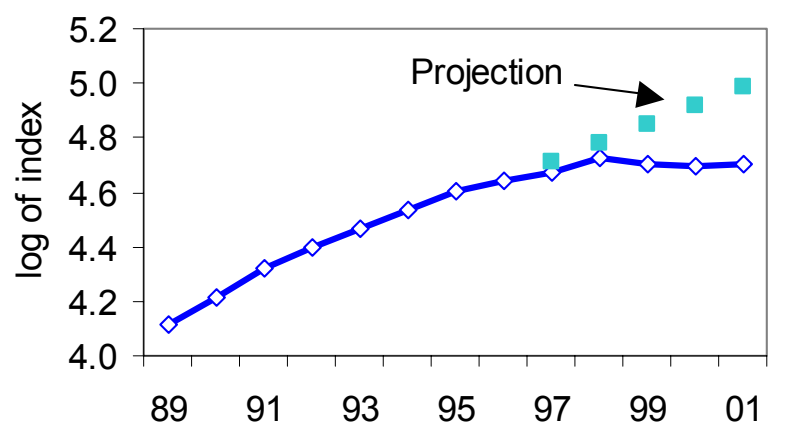

Notes: Real GDP is measured in trillions of constant 1995 won, and expressed in logarithms in the chart. The GDP deflator is an index number equal to 100 in 1995 and expressed in logarithms in the chart. The exchange rate is measured in won per dollar and is expressed in logarithms in the chart. The trends were calculated as described in the text. 


\section{FIGURE 4}

GOVERnMEnt SPENDing, REVEnUE AND FISCAL REFORMS IN KOREA

(a) Government Revenue

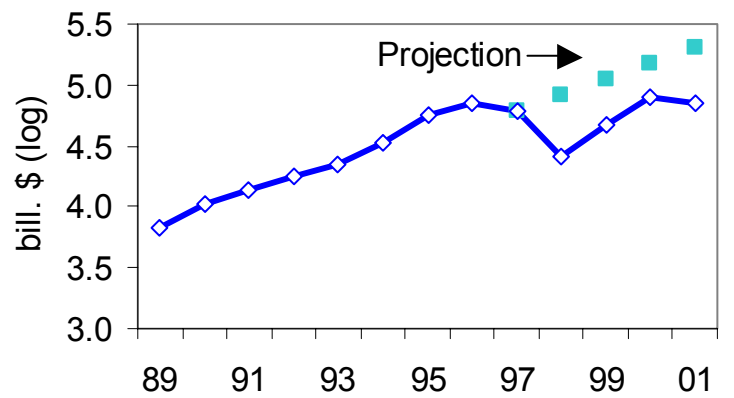

(c) Government Purchases

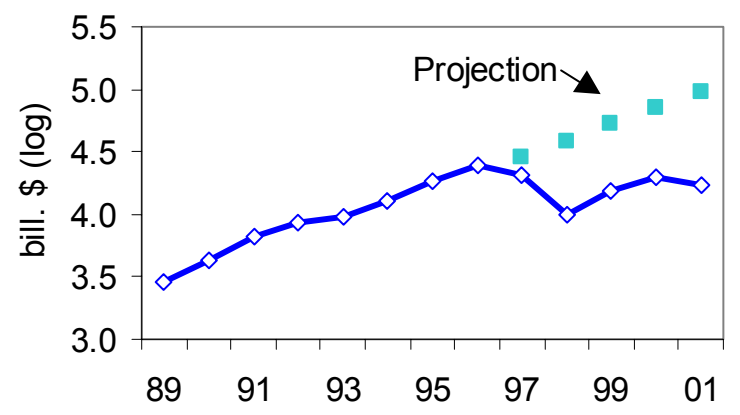

(e) Government Transfers

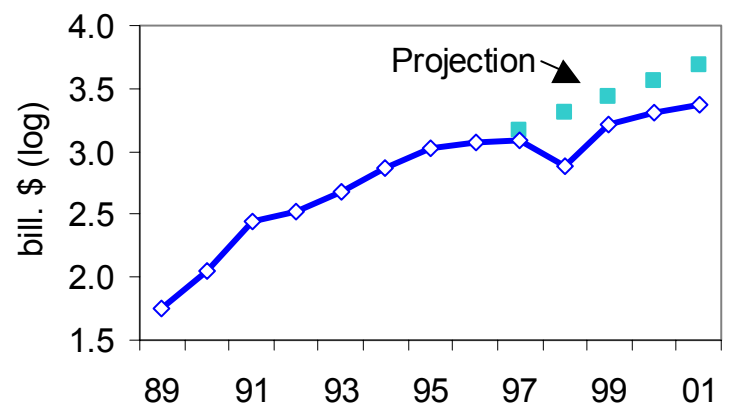

(b) Revenue Changes due to Crisis

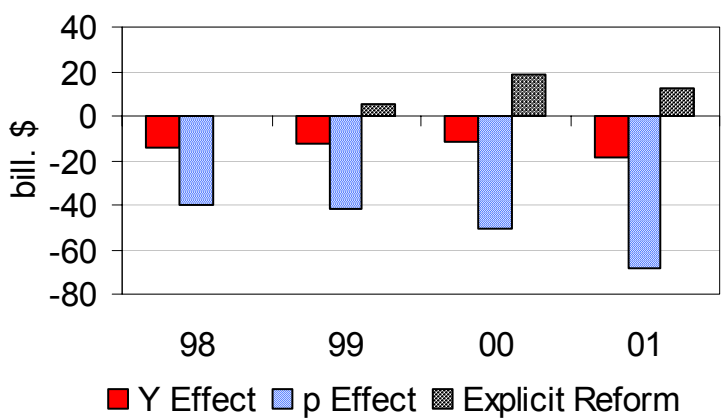

(d) Decline in Purchases due to Crisis

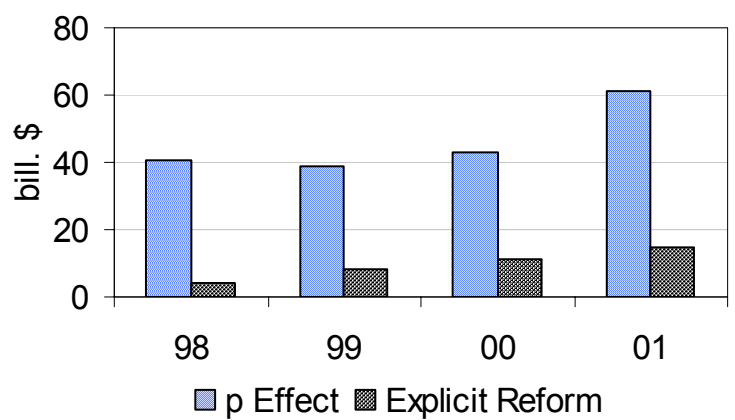

(f) Decline in Transfers due to Crisis

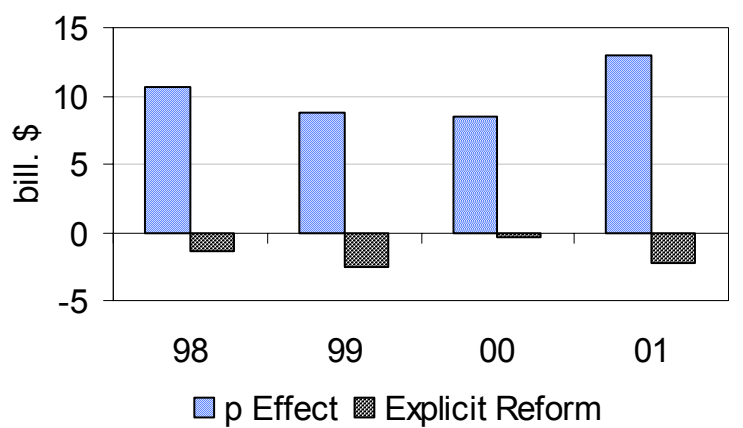

Notes: The trends in government revenue, purchases and transfers were estimated as described in the text. Negative "revenue changes" indicate an additional fiscal cost to the government. Positive "declines" in purchases and transfers indicate additional financing for the government. Calculations used in defining the time series in (b), (d) and (f) are described in the text. 
FIGURE 5

ReVEnUe From DebT Deflation IN MeXico, 1994-1999

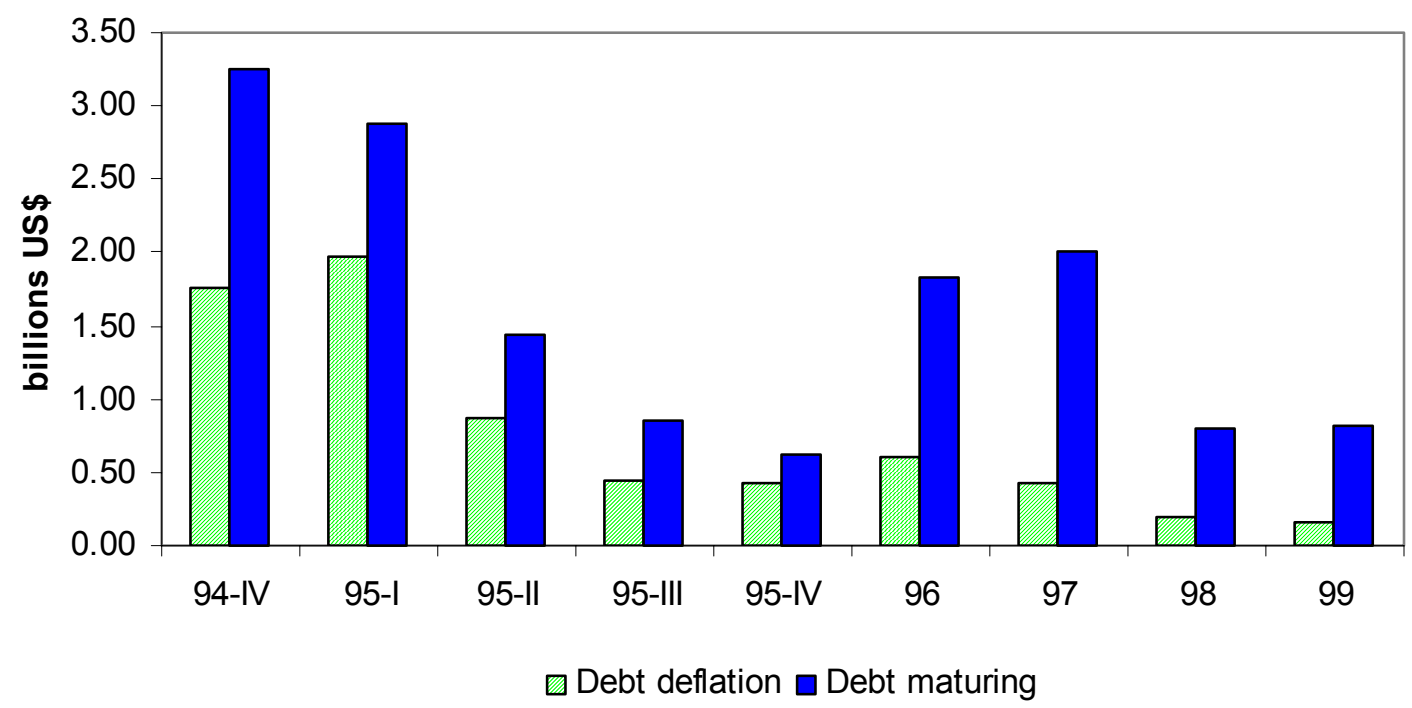

Notes: The quantity of debt maturing is sum of the face values (in pesos) of all debt maturing within each time period divided by the exchange rate (pesos/dollar). Debt deflation is unanticipated revenue from the decline in the dollar value of domestic debt. See the text for the details of the calculations and data. 
FIGURE 6

\section{Estimated TREnd PATHS FOR MEXICAN TIME SERIES}

(a) Real GDP ( $Y$ )

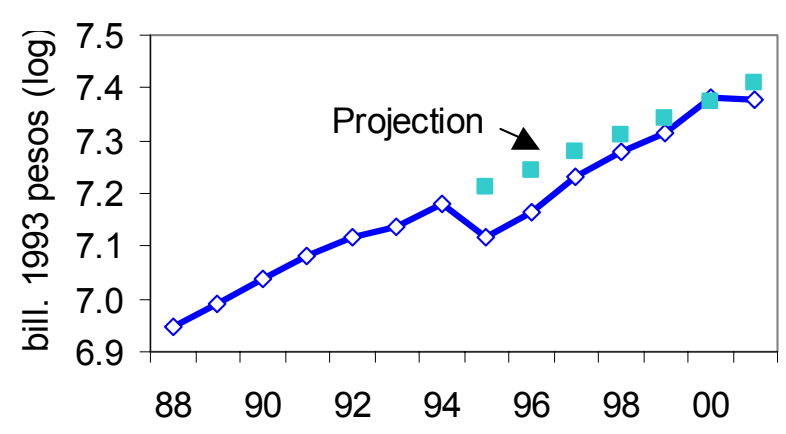

(c) Exchange Rate (S)

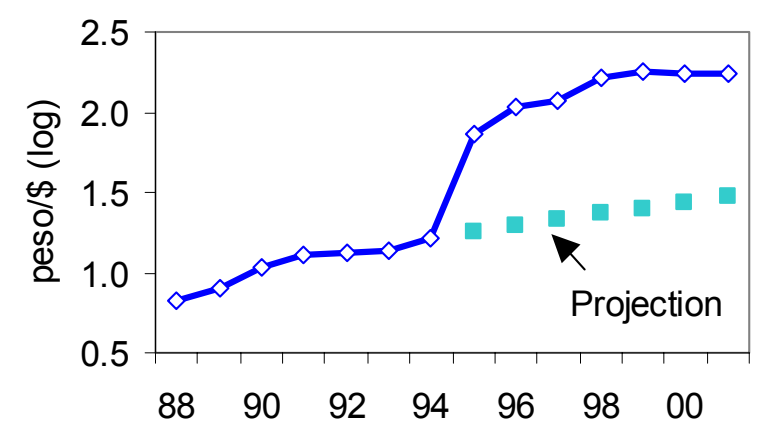

(b) GDP Deflator / Exch. Rate (p)

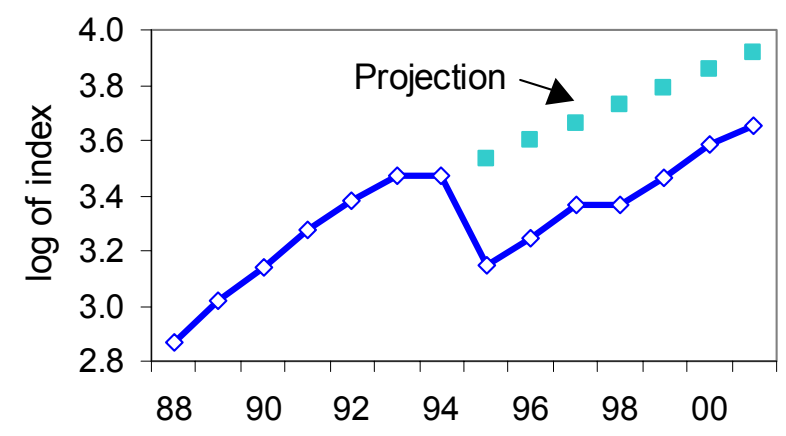

(d) GDP Deflator $(P)$

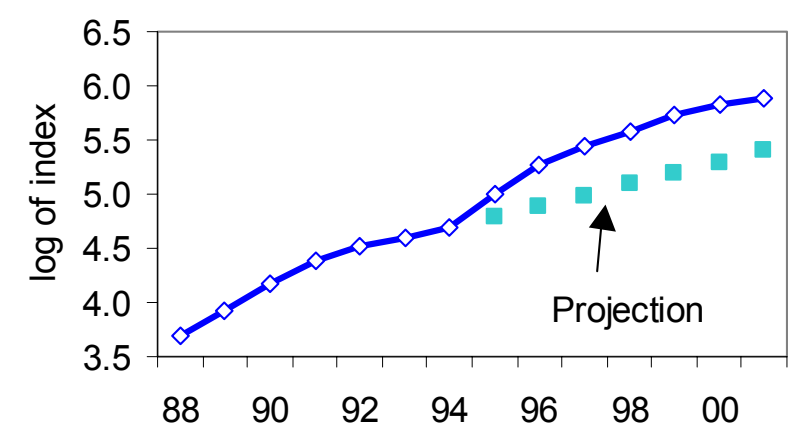

Notes: Real GDP is measured in billions of constant 1993 pesos, and expressed in logarithms in the chart. The GDP deflator is an index number equal to 100 in 1993 and expressed in logarithms in the chart. The exchange rate is measured in pesos per dollar and is expressed in logarithms in the chart. The trends were calculated as described in the text. 


\section{FIGURE 7}

Government Spending, REVEnUe AND Fiscal REFORMS In MEXICO

(a) Government Revenue

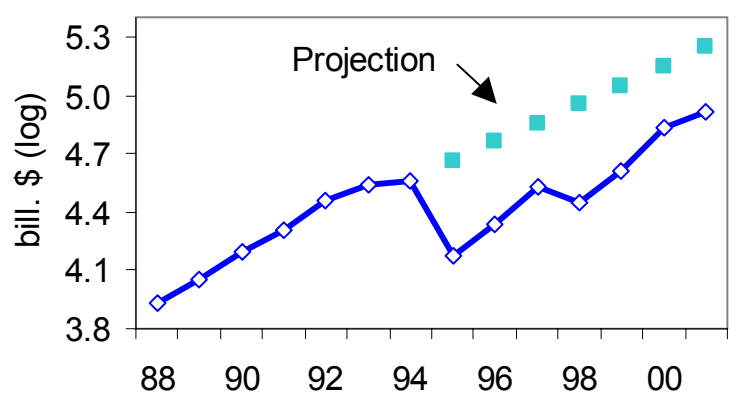

(c) Government Purchases

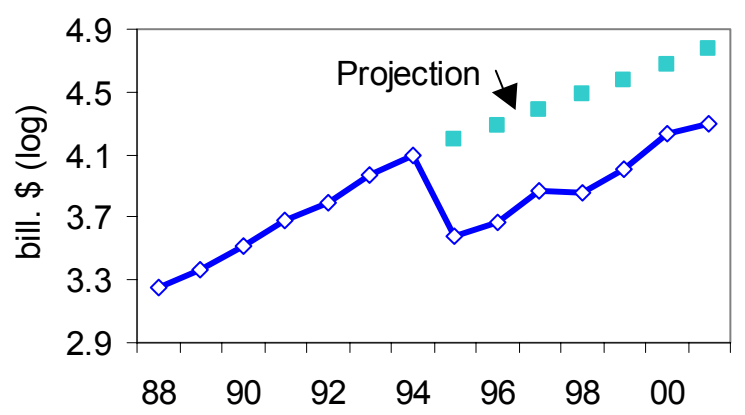

(e) Government Transfers

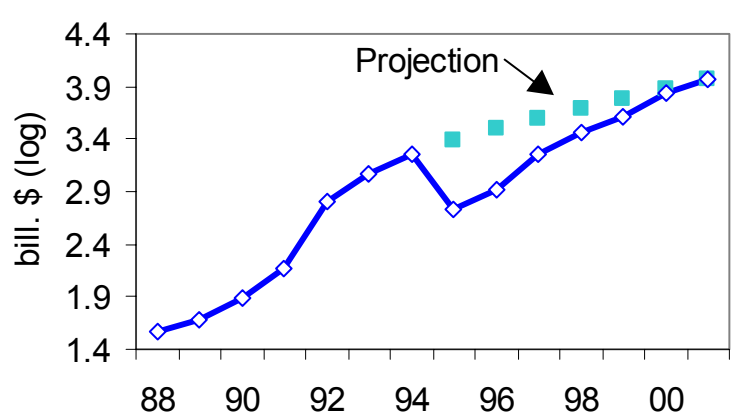

(b) Revenue Changes due to crisis

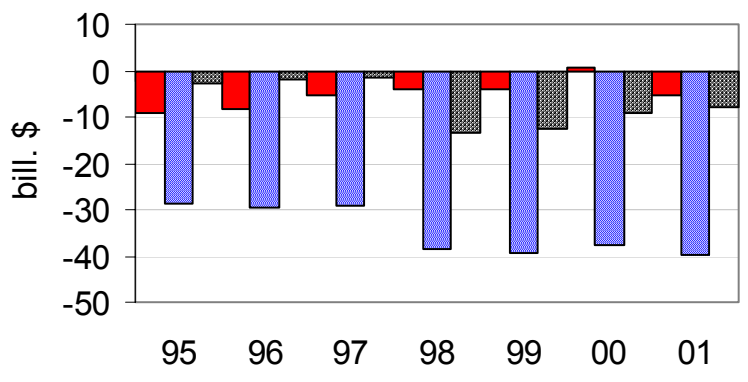

Y Effect $\square$ p Effect $\square$ Explicit reform

(d) Decline in Purchases due to Crisis

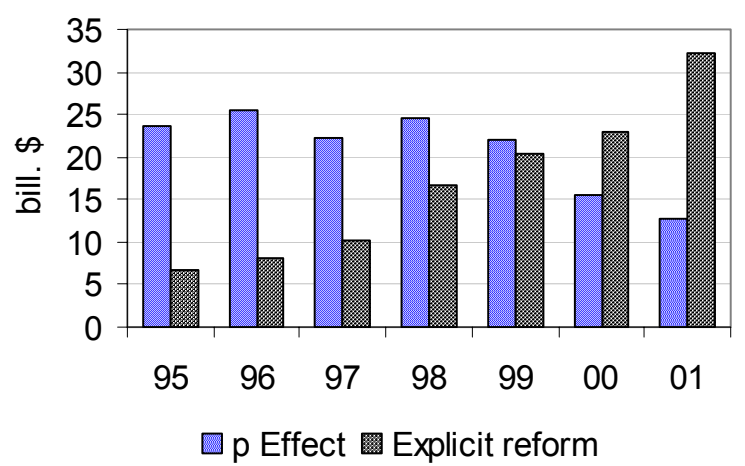

(f) Decline in Transfers due to Crisis

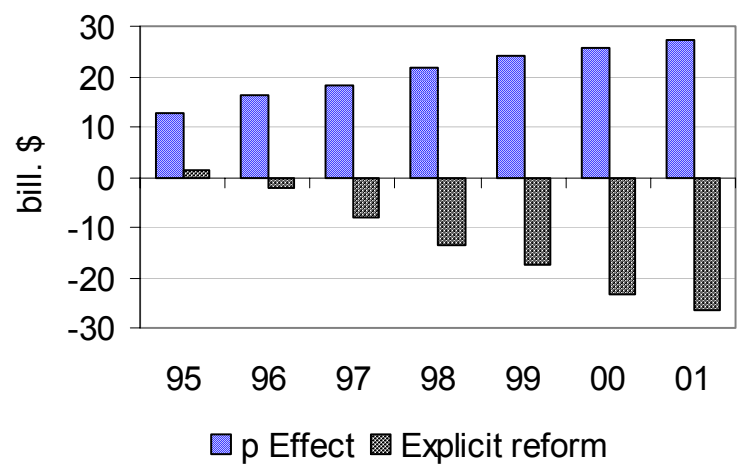

Notes: The trends in government revenue, purchases and transfers were estimated as described in the text. Negative "revenue changes" indicate an additional fiscal cost to the government. Positive "declines" in purchases and transfers indicate additional financing for the government. Calculations used in defining the time series in (b), (d) and (f) are described in the text. 


\section{FIGURE 8}

REVENUE FROM DEBT DEFLATION IN TURKEY, 2001-2009

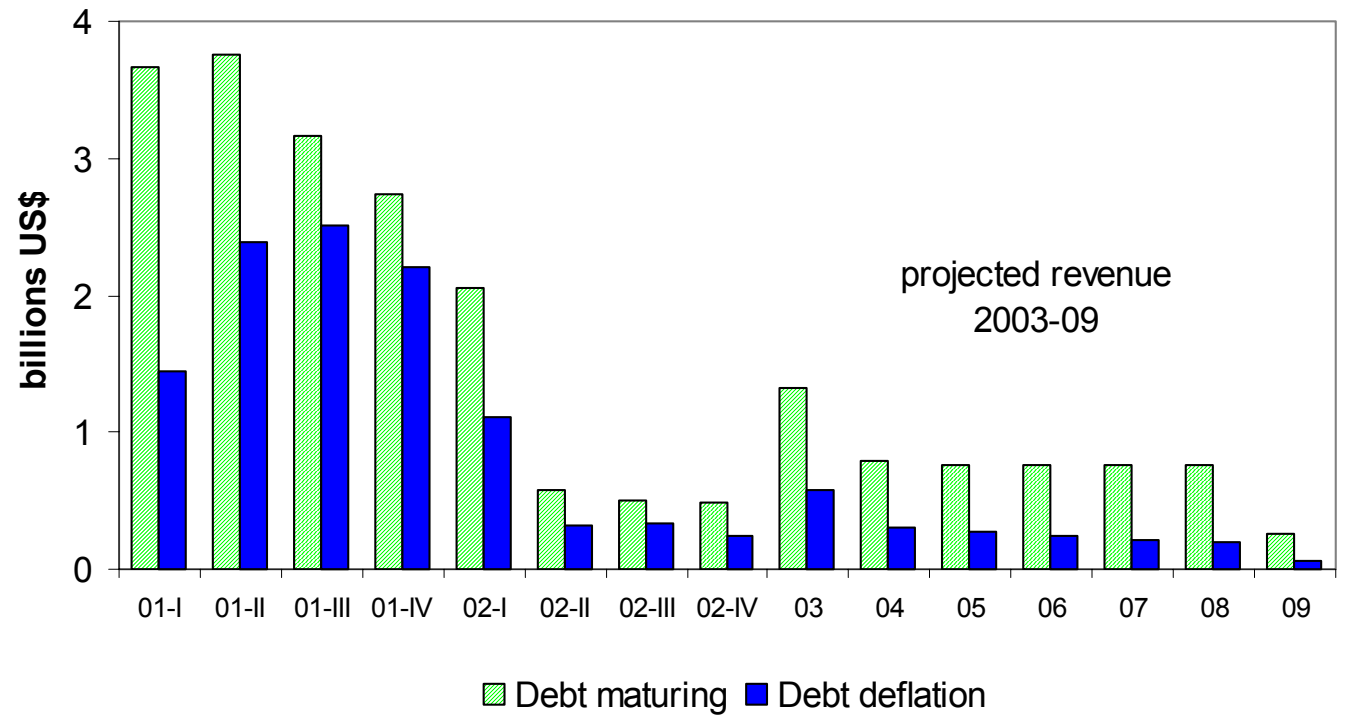

Notes: The quantity of debt maturing is sum of the face values (in TL) of all debt maturing within each time period divided by the exchange rate (TL/dollar). Debt deflation is unanticipated revenue from the decline in the dollar value of domestic debt. See the text for the details of the calculations and data. 


\section{FIGURE 9}

ESTIMATED TREND PATHS FOR TURKISH TIME SERIES

(a) Real GDP (Y)

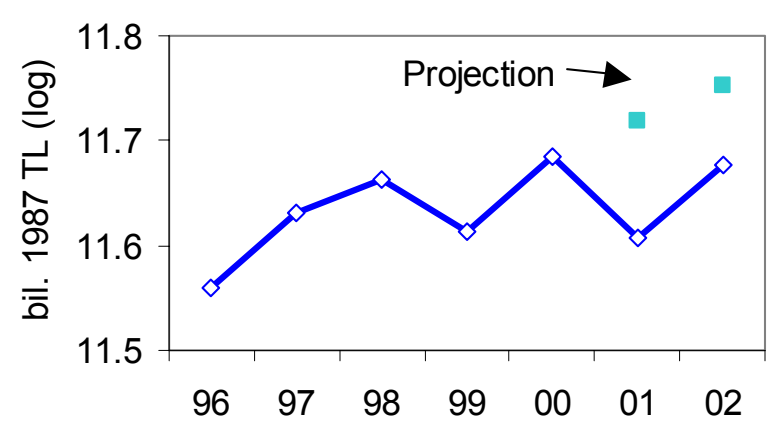

(c) Exchange Rate (S)

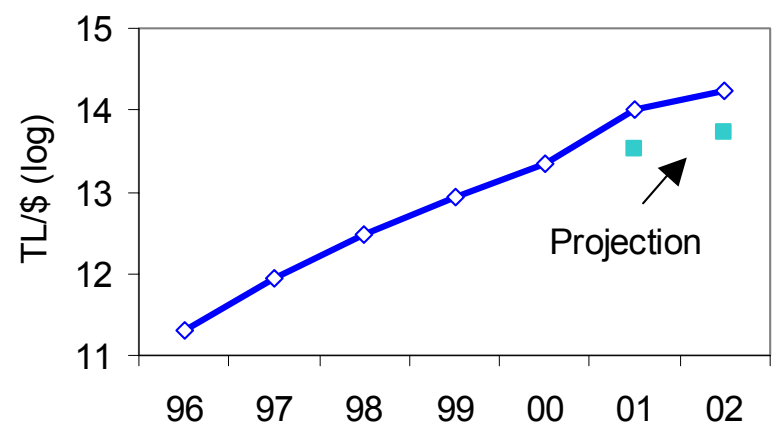

(b) GDP Deflator / Exch. Rate (p)

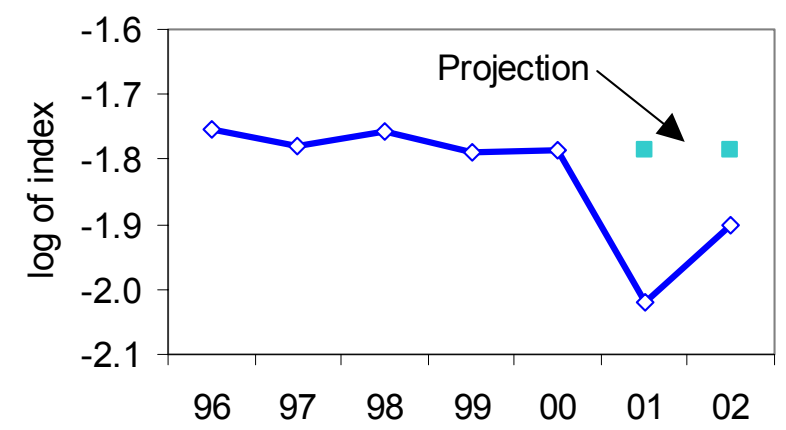

(d) GDP Deflator $(P)$

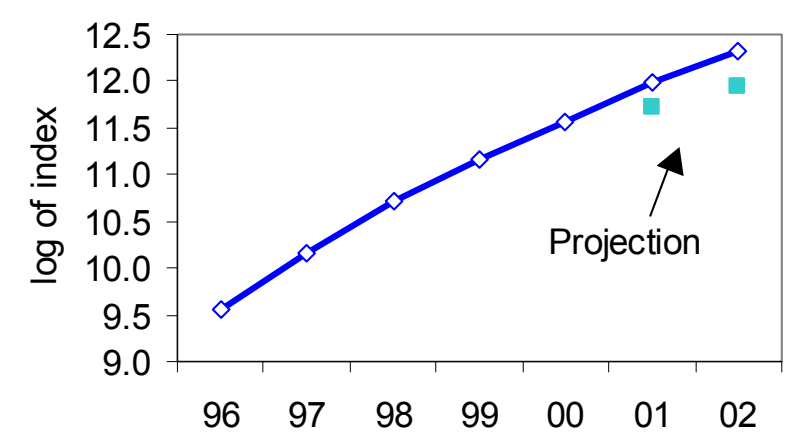

Notes: Real GDP is measured in billions of constant 1987 TL, and expressed in logarithms in the chart. The GDP deflator is an index number equal to 100 in 1987 and expressed in logarithms in the chart. The exchange rate is measured in TL per dollar and is expressed in logarithms in the chart. The trends were calculated as described in the text. 
FIGURE 10

GOVERnMENT SPENDING, REVENUE AND FisCAL REFORMS IN TURKEY

(a) Government Revenue

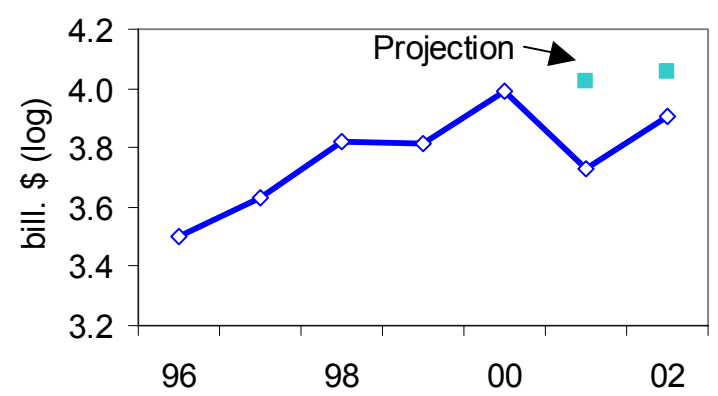

(c) Government Purchases

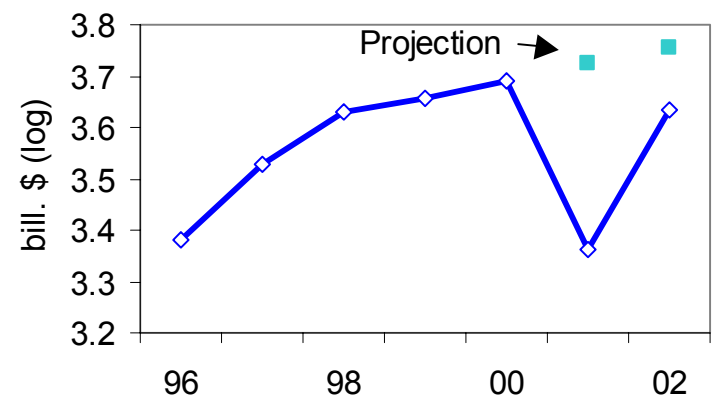

(e) Government Transfers

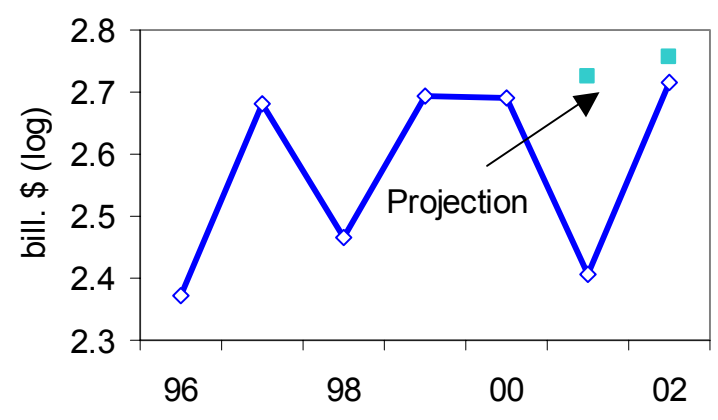

(b) Revenue Changes due to Crisis

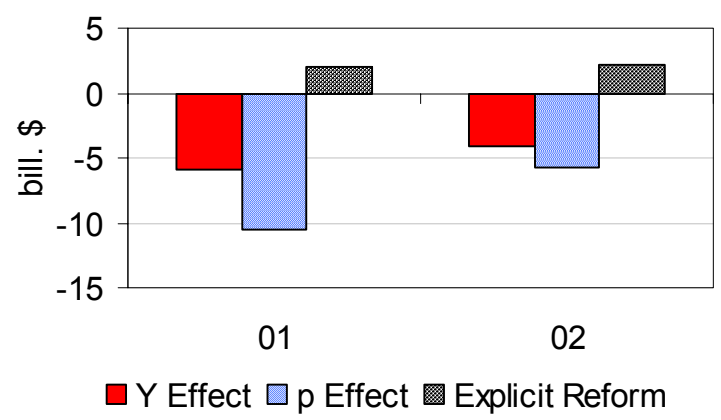

(d) Decline in Purchases due to Crisis

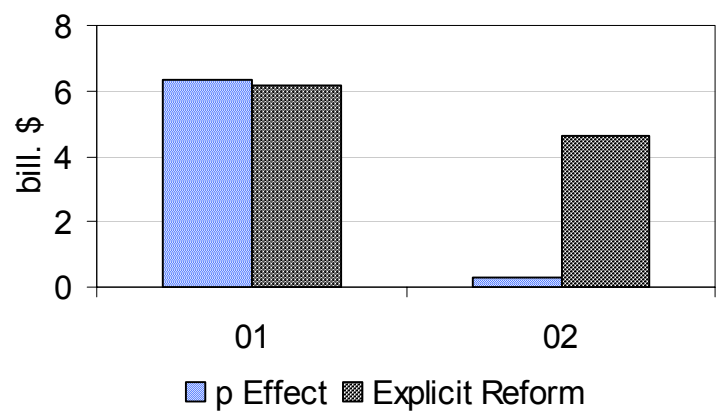

(f) Decline in Transfers due to Crisis

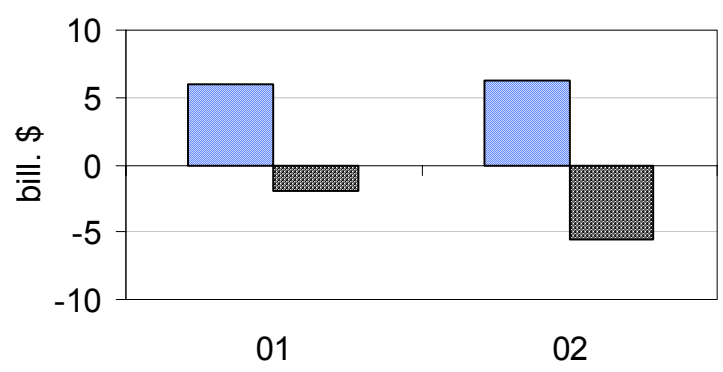

$\square p$ Effect $\square$ Explicit Reform

Notes: The trends in government revenue, purchases and transfers were estimated as described in the text. Negative "revenue changes" indicate an additional fiscal cost to the government. Positive "declines" in purchases and transfers indicate additional financing for the government. Calculations used in defining the time series in (b), (d) and (f) are described in the text. 


\section{References}

Burnside, Craig (2002) "Debt and Fiscal Sustainability in Turkey: 1994-2002," mimeo, World Bank.

Burnside, Craig, Martin Eichenbaum, and Sergio Rebelo (2001) "Prospective Deficits and the Asian Currency Crisis," Journal of Political Economy, 109, 1155-97.

Burnside, Craig, Martin Eichenbaum, and Sergio Rebelo (2003) "On the Fiscal Implications of Twin Crises," in Michael P. Dooley and Jeffrey A. Frankel, eds. Managing Currency Crises in Emerging Markets. Chicago: University of Chicago Press.

Burstein, Ariel, Martin Eichenbaum, and Sergio Rebelo (2002) "Why Are Rates of Inflation So Low After Large Devaluations?" mimeo, Northwestern University.

Burstein, Ariel, Joao Neves, and Sergio Rebelo (2002) "Distribution Costs and Real Exchange Rate Dynamics During Exchange-Rate-Based Stabilizations," forthcoming, Journal of Monetary Economics.

Cagan, Phillip (1956) "Monetary Dynamics of Hyperinflation," in Milton Friedman, ed. Studies in the Quantity Theory of Money. Chicago: University of Chicago Press.

Calvo, Guillermo (1987) "Balance of Payments Crises in a Cash-in-Advance Economy," Journal of Money Credit and Banking, 19, 19-32.

Caprio, Jr., Gerard and Daniela Klingebiel (1996) "Bank Insolvencies: Cross Country Experience," Policy Research Working Paper 1620, World Bank.

Cochrane, John (2001) "Long-term Debt and Optimal Policy in the Fiscal Theory of the Price Level," Econometrica, 69, 69-116.

Corsetti, Giancarlo and Luca Dedola (2002) "Macroeconomics of International Price Discrimination," mimeo, University of Rome III.

Corsetti, Giancarlo and Bartosz Mackowiak (2002) "Nominal Debt and the Dynamics of Currency Crises," mimeo, University of Rome III..

Corsetti, Giancarlo, Paolo Pesenti, and Nouriel Roubini (1999) "What Caused the Asian Currency and Financial Crisis?" Japan and the World Economy 11, 305-373.

Daniel, Betty (2001) "A Fiscal Theory of Currency Crises," International Economic Review, 42, 969-88.

Drazen, Allan, and Elhanan Helpman (1987) "Stabilization with Exchange Rate Management," Quarterly Journal of Economics, 102, 835-55.

Dupor, William (2000) "Exchange Rates and the Fiscal Theory of the Price Level," Journal of Monetary Economics, 45, 613-30.

Easterly, William and Klaus Schmidt-Hebbel (1994) "The Macroeconomics of Public Sector Deficits: A Synthesis," in W. Easterly, K. Schmidt-Hebbel and C.A. Rodriguez, eds., Public Sector Deficits and Macroeconomic Performance. New York: World Bank. 
Feenstra, Robert (1985) "Anticipated Devaluations, Currency Flight, and Direct Trade Controls in a Monetary Economy," American Economic Review, 75, 386-401.

Flood, Robert and Peter Garber (1984) "Collapsing Exchange Rate Regimes: Some Linear Examples," Journal of International Economics, 17, 1-13.

Jeanne, Olivier and Jeromin Zettelmeyer (2000) "International Bailouts, Financial Transparency and Moral Hazard," mimeo, International Monetary Fund.

Krugman, Paul (1979) "A Model of Balance of Payments Crises," Journal of Money, Credit and Banking, 11, 311-25.

Lahiri, Amartya and Carlos Végh (2003) "Output Costs, BOP Crises, and Optimal Interest Rate Policy," forthcoming, Journal of Political Economy.

Lindgren, Carl-Johan, Gillian G.H. Garcia and Matthew I. Saal (1996) Bank Soundness and Macroeconomic Policy. Washington, DC: International Monetary Fund.

Morris, Stephen (1995) "Inflation Dynamics and the Parallel Market for Foreign Exchange," Journal of Development Economics, 46, 295-316.

Obstfeld, Maurice (1986) "Speculative Attack and the External Constraint in a Maximizing Model of the Balance of Payments," Canadian Journal of Economics, 29, 1-20.

Persson, Mats, Torsten Persson, and Lars E. O. Svensson (1998) "Debt, Cash Flow and Inflation Incentives: A Swedish Example," in Guillermo A. Calvo and Mervin King, editors: The Debt Burden and its Consequences for Monetary Policy. New York: St. Martin's Press.

Pinto, Brian (1990) "Black Market Premia, Exchange Rate Unification, and Inflation in Sub-Saharan Africa," World Bank Economic Review, 3, 321-38.

Rebelo, Sergio and Carlos Végh (2002) "When is it Optimal to Abandon a Fixed Exchange Rate?," mimeo, Northwestern University, March.

Sargent, Thomas J. and Neil Wallace (1973) "The Stability of Models of Money and Growth with Perfect Foresight," Econometrica, 41, 1043-8.

Sims, Christopher (1994) "A Simple Model for the Determination of the Price Level and the Interaction of Monetary and Fiscal Policy," Economic Theory, 4, 381-99.

Standard and Poor's (2000) "Global Financial System Stress: 15 Display Troubled Credit Quality," RatingsDirect, July 31.

Wijnbergen, Sweder Van (1991) "Fiscal Deficits, Exchange Rate Crises and Inflation," Review of Economic Studies, 58, 81-92.

Woodford, Michael (1995) "Price Level Determinacy Without Control of a Monetary Aggregate," Carnegie-Rochester Conference Series on Public Policy, 43, 1-46. 


\section{Data Sources}

Exchange Rates For monthly and annual data we used the International Monetary Fund's International Financial Statistics (IFS) series AE...ZF (end-of-period) and AF...ZF (periodaverage) which are measured in local currency units per U.S. dollar. We used end-of-period figures when converting end-of-period stocks measured in units of local currency to dollar measures. We used period-average figures when converting local currency flows to dollars.

CPI For monthly data we used the IFS series $64 \ldots$ ZF.

Monetary Base For monthly end-of-period data we used the IFS data series reserve money, 14...ZF.

Interest Rates For Korea we used data from the IFS on the money market interest rate (60B..ZF), time deposits at deposit money banks (60L..ZF), lending rates of deposit money banks (60P..ZF), and yields on national housing bonds $(61 \ldots Z \mathrm{ZF})$. These data all pertain to won-denominated assets. We computed equivalent dollar returns using our exchange rate data for Korea.

For Mexico and Turkey we used data on Emerging Market Bond Index (EMBI) and EMBI+ spreads. We used the EMBI spread for Mexico and the EMBI+ spread for Turkey (there is no EMBI spread for Turkey). Our source for these data was Bloomberg. The data pertain to the spreads over US interest rates on dollar-denominated assets. We combined the spread information with information on 3-month US Treasury Bill rates from the Board of Governors of the Federal Reserve System Release H.15 (http://www.federalreserve.gov/ releases/) in order to generate dollar interest rates.

Cost of the Banking Sector Bailout For Korea, we use the estimate provided by Standard and Poor's (2000). As of December 1999, they estimated that the fiscal cost of the banking crisis would be roughly 24 percent of 1997 GDP, or 114.4 billion dollars.

For Mexico, Lindgren, Garcia, and Saal (1996) estimate the fiscal cost of the crisis to be 6.5 percent of GDP, which amounts to 27 billion dollars. On the other hand, Caprio and Klingebiel (1996) estimate the cost to be between 12 and 15 percent of GDP, with the upper bound translating into 63 billion dollars.

For Turkey we use the estimate provided by Burnside (2002), 36.2 billion dollars, which is based on a detailed analysis of the changes in Turkey's "noncash" domestic debt stock between January and December 2001.

National Income Accounts Data We use national income accounts data to get measures of real and nominal GDP, their expenditure and production components, and the relevant deflators. Our data for Korea were obtained from the Bank of Korea website, http://www.bok.or.kr/, Statistics, Statistics Database, National Accounts page, HLHA, HLHB, HLHC, and HLHD sections. Our data for Mexico were obtained from the website of Instituto Nacional de Estadística, Geografía e Informática (INEGI), http://www.inegi.gob.mx /difusion/espanol/fiecons.html. For Turkey our data were obtained from the Bank of Turkey's Electronic Data Delivery System (EDDS) website, http://tcmbf40.tcmb.gov.tr/cbt.html, General Statistics, "GNP at Current Prices," and "GNP at Fixed Prices" pages. 
Fiscal Data For Korea we measured government purchases as the sum of the government consumption and government capital formation series in the national income accounts (described above). For revenue, we used the series "revenue of general government" from the "Income/outlay of general government" table on the National Statistical Office's website http://www.nso.go.kr/eng/. For transfer spending, we used the sum of the series "subsidies," "social security benefits," "social assistance benefits," and "current transfers N.E.C." from the same table.

For Mexico we measured government purchases as the average of two series: (i) the sum of the government consumption expenditure and government investment expenditure series in the national income accounts (described above) and (ii) the sum of the series for current expenditures (excluding transfers and interest) and capital expenditure provided by Banco de Mexico at http://www.banxico.org.mx/siteBanxicoINGLES/eInfoFinanciera/FSinfoFinanciera.html. For revenue, we used the series "consolidated budgetary revenues" from the same Banco de Mexico website. For Mexico we used the sum of two series from the same website: (i) "net transfers" and (ii) a fraction of "revenue sharing to state and local governments" corresponding to the share of federal transfer spending in federal spending other than transfers to state and local governments.

For Turkey we measured government purchases as the sum of government consumption expenditure and public sector investment expenditure as defined in the national income accounts (described above). For revenue we used the series "revenues" from the page "Consolidated Budget (Treasury)" at the Bank of Turkey EDDS website (describe above). For transfers we used the series "other transfers" from the same page.

Data on Nominal Debt Our data on Korea's stocks of different domestic debt instruments were obtained from the National Statistics Office website, http://www.stat.go.kr/cgibin/bbs/imain.cgi, and were originally sourced from the Bank of Korea and the Ministry of Finance and Economy.

Our data for Mexico's stocks of different domestic debt instruments were obtained from the Ministry of Finance and Public Credit (SHCP): http://www.shcp.gob.mx/english/eofp /cuadros/E01I1994.html.

Our data for Turkey's stocks of different domestic debt instruments at the end of January 2001 were obtained from the Turkish Treasury website, http://www.treasury.gov.tr/ english/debtstat.htm, 2001 spreadsheet, Table 4: Maturity Composition of Outstanding Debt. 


\section{Technical Appendix}

A Discrete Time Approximation to the Model In this section we describe a discrete time approximation to our model. We divide time into small intervals each of length $n$ years. So, for example, $n=1 / 12$ would imply that time was being measured in months. The variable $t$ is used here to index these time intervals. All flow variables defined in the main text are measured as flows per small interval but are expressed at annual rates.

The Representative Household The representative agent maximizes lifetime utility, defined as:

$$
\max \sum_{t=0}^{\infty}(1+\rho n)^{-t} n \frac{c_{t}^{1-\sigma}-1}{1-\sigma}
$$

where

$$
c_{t}=\left(c_{t}^{T}\right)^{\omega}\left(c_{t}^{N}\right)^{1-\omega} .
$$

The household's disposable income is

$$
y_{t}^{D}=y_{t}+\frac{r B}{S_{t}}+\frac{P_{t}}{S_{t}} \hat{v}_{t}+\tilde{v}_{t}-\tau_{t} .
$$

The representative agent's flow budget constraint for $t \geq 0$ is given by:

$$
a_{t}=(1+n r) a_{t-1}+Z_{t}-\frac{M_{t}-M_{t-1}}{S_{t}}
$$

where

$$
Z_{t}=n\left(y_{t}^{D}-p_{t}^{T} c_{t}^{T}-p_{t}^{N} c_{t}^{N}\right) .
$$

Here $p_{t}^{N}=P_{t}^{N} / S_{t}, p_{t}^{T}=P_{t}^{T} / S_{t}=1+\delta p_{t}^{N}$, and $Z_{t} / n$ represents household saving, measured at annual rates.

Iterating on the flow budget constraint starting at time 0 , we have

$$
\begin{aligned}
a_{-1} & =(1+n r)^{-1} a_{0}-(1+n r)^{-1}\left(Z_{0}-\frac{M_{0}-M_{-1}}{S_{0}}\right) \\
& =(1+n r)^{-t} a_{t-1}-\sum_{j=0}^{t-1}(1+n r)^{-(j+1)}\left(Z_{j}-\frac{M_{j}-M_{j-1}}{S_{j}}\right) .
\end{aligned}
$$

Imposing the condition $\lim _{t \rightarrow \infty}(1+n r)^{-t} a_{t-1}=0$, we obtain the intertemporal budget constraint:

$$
a_{-1}+\sum_{t=0}^{\infty}(1+n r)^{-(t+1)} Z_{t}=\sum_{t=0}^{\infty}(1+n r)^{-(t+1)} \frac{M_{t}-M_{t-1}}{S_{t}} .
$$

The cash-in-advance constraint is

$$
\eta\left(P_{t}^{T} c_{t}^{T}+P_{t}^{N} c_{t}^{N}\right) \leq M_{t}
$$


Solving the Household Problem The Lagrangean for the household's problem is

$$
\begin{aligned}
L= & \max \sum_{t=0}^{\infty}(1+\rho n)^{-t} n \frac{\left[\left(c_{t}^{T}\right)^{\omega}\left(c_{t}^{N}\right)^{1-\omega}\right]^{1-\sigma}-1}{1-\sigma}+ \\
& +\sum_{t=0}^{\infty} \Lambda_{t}\left[(1+n r) a_{t-1}+Z_{t}-\frac{M_{t}-M_{t-1}}{S_{t}}-a_{t}\right] \\
& +\sum_{t=0}^{\infty} \Theta_{t}\left[\frac{M_{t}}{S_{t}}-\eta\left(p_{t}^{T} c_{t}^{T}+p_{t}^{N} c_{t}^{N}\right)\right]
\end{aligned}
$$

subject to (6.4).

The first-order conditions, other than the constraints, are

$$
\begin{array}{rll}
c_{t}^{T}: & (1+\rho n)^{-t} n\left[\left(c_{t}^{T}\right)^{\omega}\left(c_{t}^{N}\right)^{1-\omega}\right]^{1-\sigma} \omega\left(c_{t}^{T}\right)^{-1}=\left(\Lambda_{t} n+\Theta_{t} \eta\right) p_{t}^{T} \\
c_{t}^{N}: & (1+\rho n)^{-t} n\left[\left(c_{t}^{T}\right)^{\omega}\left(c_{t}^{N}\right)^{1-\omega}\right]^{1-\sigma}(1-\omega)\left(c_{t}^{N}\right)^{-1}=\left(\Lambda_{t} n+\Theta_{t} \eta\right) p_{t}^{N} \\
a_{t}: & \Lambda_{t}=\Lambda_{t+1}(1+n r) \\
M_{t}: & \Lambda_{t}=\Lambda_{t+1} \frac{S_{t}}{S_{t+1}}+\Theta_{t}
\end{array}
$$

It is convenient to define: $\lambda_{t}=\Lambda_{t}(1+\rho n)^{t}$ and $\theta_{t}=\Theta_{t}(1+\rho n)^{t}$. Noting that $r=\rho$ we then have:

$$
\begin{aligned}
n\left[\left(c_{t}^{T}\right)^{\omega}\left(c_{t}^{N}\right)^{1-\omega}\right]^{1-\sigma} \omega\left(c_{t}^{T}\right)^{-1} & =\left(\lambda_{t} n+\theta_{t} \eta\right) p_{t}^{T} \\
n\left[\left(c_{t}^{T}\right)^{\omega}\left(c_{t}^{N}\right)^{1-\omega}\right]^{1-\sigma}(1-\omega)\left(c_{t}^{N}\right)^{-1} & =\left(\lambda_{t} n+\theta_{t} \eta\right) p_{t}^{N} \\
\lambda_{t} & =\lambda_{t+1} \\
\lambda_{t} & =\lambda_{t+1} \frac{S_{t}}{S_{t+1}} /(1+\rho n)+\theta_{t}
\end{aligned}
$$

The Government Budget Constraint The government's flow budget constraint is:

$$
b_{t}=(1+n r) b_{t-1}+X_{t}-\frac{M_{t}-M_{t-1}}{S_{t}}
$$

where

$$
X_{t}=n\left(g_{t}^{T}+p_{t}^{N} g_{t}^{N}+\frac{P_{t}}{S_{t}} \hat{v}_{t}+\tilde{v}_{t}+v_{t}^{*}-\tau_{t}+r \frac{B}{S_{t}}\right) .
$$

Here $X_{t} / n$ represents the government's primary surplus.

The government's lifetime budget constraint at time 0 is given by

$$
b_{-1}+\sum_{t=0}^{\infty}(1+n r)^{-(t+1)} X_{t}=\sum_{t=0}^{\infty}(1+n r)^{-(t+1)} \frac{M_{t}-M_{t-1}}{S_{t}}
$$


Aggregate Resource Constraint The equilibrium condition for nontradables is given by:

$$
y_{t}^{N}=c_{t}^{N}+\delta c_{t}^{T}+g_{t}^{N}
$$

If we aggregate (6.3) and (6.11) we get a flow resource constraint for tradables:

$$
a_{t}-b_{t}=(1+n r)\left(a_{t-1}-b_{t-1}\right)+Z_{t}-X_{t},
$$

or

$$
f_{t}=(1+n r) f_{t-1}+Z_{t}-X_{t}
$$

where $f_{t}=a_{t}-b_{t}$ is the country's net foreign asset position. Notice that

$$
Z_{t}-X_{t}=\left(n y_{t}^{T}-g_{t}^{T}-c_{t}^{T}-v_{t}^{*}\right)
$$

The lifetime resource constraint for tradables is

$$
f_{-1}+\sum_{t=0}^{\infty}(1+n r)^{-(t+1)}\left(Z_{t}-X_{t}\right)=0 .
$$

The Sustainable Fixed Exchange Rate Regime We assume that the government holds the exchange rate constant at some level $S$. We also assume that $g_{t}^{T}=g^{T}, g_{t}^{N}=g^{N}, y_{t}^{T}=y^{T}$, $y_{t}^{N}=y^{N}, \tau_{t}^{L}=\tau^{L}, \hat{v}_{t}=\hat{v}, \tilde{v}_{t}=\tilde{v}, v_{t}^{*}=v^{*}$, and $M_{t}=M$ for all $t$. We conjecture that the solution to the model in this case has the property that $P_{t}^{N}=P^{N}$ for all $t$ and, therefore, that $P_{t}=P^{T}=S+\delta P^{N}$ for all $t$. It follows that $p_{t}^{N}=p^{N}=P^{N} / S$ and $p_{t}^{T}=p^{T}=1+\delta p^{N}$ for all $t$. We also have $c_{t}^{N}=c^{N}, c_{t}^{T}=c^{T}$, and $a_{t}=a_{-1}$ for all $t$.

$>$ From (6.13) the consumption of nontradables is given by

$$
c^{N}=y^{N}-g^{N}-\delta c^{T} .
$$

The lifetime resource constraint for tradables, (6.15), combined with (6.13) implies

$$
c^{T}=r f_{-1}+y^{T}-g^{T}-v^{*} .
$$

From these it is convenient to solve for

$$
c=\left(c^{T}\right)^{\omega}\left(c^{N}\right)^{1-\omega} .
$$

Next consider the household's problem. Notice that the household's first-order condition for $a_{t}$ implies $\lambda_{t}=\lambda$ for all $t$. From this result and the first-order condition for $M_{t}$ we have $\theta_{t}=\rho n \lambda /(1+\rho n)$ for all $t$. Eliminating $\theta$, the household's first-order conditions for $c^{T}$ and $c^{N}$ can be rewritten as

$$
\begin{aligned}
n c^{1-\sigma} \omega / c^{T} & =\lambda\left(n+\frac{\rho n}{1+\rho n} \eta\right)\left(1+\delta p^{N}\right) \\
n c^{1-\sigma}(1-\omega) / c^{N} & =\lambda\left(n+\frac{\rho n}{1+\rho n} \eta\right) p^{N}
\end{aligned}
$$

Given our previous results, the unknowns in these two equations are $\lambda$ and $p^{N}$. Taken together the two equations imply

$$
p^{N}=\frac{(1-\omega) c^{T}}{\omega c^{N}-(1-\omega) c^{T} \delta} .
$$


and $P^{N}=p^{N} S$. Hence

$$
p^{T}=1+\delta p^{N}
$$

and $P^{T}=p^{T} S$.

When we calibrate the model we choose the arbitrary normalization $y^{T}=y^{N}=1$ and set the relative price of nontradables to a value $p^{N}$ consistent with the share of nontradables in GDP in the model, $p^{N} /\left(1+p^{N}\right)$, being equal to the corresponding value in our data set. We set $g^{T}$ and $g^{N}$ consistent with the data, and set $v^{*}=0$. Notice that this implies that (6.16), (6.17), and (6.19) then form a system of three equations which can be solved for three unknowns: $c^{T}, c^{N}$, and $f_{-1}$.

Our results thus far can be used to determine the steady state values of

$$
\lambda=\frac{n(1-\omega)}{\left(n+\frac{\rho n}{1+\rho n} \eta\right) p^{N} c^{N}} c^{1-\sigma}
$$

and

$$
\theta=\rho n \lambda /(1+\rho n)
$$

Notice that at this point we can pin down the money supply from the cash-in-advance constraint:

$$
M=\eta\left(P^{T} c^{T}+P^{N} c^{N}\right) .
$$

We have $\tau_{t}=\tau=\tau^{T} y^{T}+\tau^{N} p^{N} y^{N}+\tau^{L}, g_{t}=g^{T}+p^{N} g^{N}$, and $v_{t}=v=\hat{v} P / S+\tilde{v}+v^{*}$. Hence, the government's lifetime budget constraint implies that

$$
\tau=r b_{-1}+g+v+r B / S
$$

The Crisis We assume that the crisis involves an increase in the present value of transfers. In particular, we assume that

$$
\begin{cases}\tilde{v}_{t}+v_{t}^{*}=\tilde{v}+v^{*} & \text { for } 0 \leq t<T^{\prime} \\ \tilde{v}_{t}+v_{t}^{*}>\tilde{v}+v^{*} & \text { for } t \geq T^{\prime}\end{cases}
$$

and that

$$
\sum_{t=0}^{\infty}(1+n r)^{-(t+1)} n \tilde{v}_{t}=\frac{\tilde{v}}{r}+\tilde{\phi}, \sum_{t=0}^{\infty}(1+n r)^{-(t+1)} n v_{t}^{*}=\frac{v^{*}}{r}+\phi^{*}
$$

Here $\phi=\tilde{\phi}+\phi^{*}$ represents the total cost of a bailout of the banking sector.

The government sets the money supply equal to $M_{t}=M_{T}(1+\mu n)^{t-T}$ for $t \geq T$. Once the information about the increase in prospective deficits arrives at time 0 , the money supply is initially fixed at some level $\underline{M}$ in order to keep the exchange rate fixed. Date $t^{*}$ is the first date at which, with the exchange rate still fixed at $S$, the demand for money falls from $\underline{M}$ to $\underline{M}(1-\chi)$, with $\chi>0$. At that point the government abandons the fixed exchange rate regime and leaves the money supply unchanged until date $T$. To summarize, we have

$$
M_{t}= \begin{cases}\frac{M}{M}(1-\chi) & 0 \leq t<t^{*} \\ \underline{M}_{T}(1+\mu n)^{t-T} & t \geq T\end{cases}
$$


The implications of the crisis for the government's lifetime budget constraint are as follows. Notice that under the sustainable fixed exchange rate regime we had

$$
X_{t}=X=n\left(g+v-\tau+r \frac{B}{S}\right)
$$

$M_{t}=M$, and consequently that $b_{-1}+X /(n r)=0$. We can substitute for $b_{-1}$ and then note that the government's lifetime budget constraint can now be rewritten

$$
\sum_{t=0}^{\infty}(1+n r)^{-(t+1)} X_{t}-\frac{X}{n r}=\sum_{t=0}^{\infty}(1+n r)^{-(t+1)} \frac{M_{t}-M_{t-1}}{S_{t}}
$$

Some Assumptions We will establish that the economy enters a post-crisis steady state at a date we define as $\bar{T}+1$. In the case of flexible prices we will show that $\bar{T}=T$. In our model of sticky prices, we assume $P_{t}^{N}=P^{N}$ for $t \leq T_{p}$. For $t>T_{p}$ we assume that $P_{t}^{N}$ moves in proportion to the exchange rate. In particular, we let $P_{t}^{N}=\left(P^{N} / S_{T_{p}}\right) S_{t}$, implying that $p_{t}^{N}=\bar{p}^{N}=P^{N} / S_{T_{p}}$ for $t>T_{p}$. We assume that $T_{p} \geq T+1{ }^{29}$ We will show that this implies $\bar{T}=T_{p}-1$.

We assume $y_{t}^{T}=y^{T}, y_{t}^{N}=y^{N}, g_{t}^{T}=g^{T}$ and $g_{t}^{N}=g^{N}$ for all $t$.

The Post-Crisis Steady State: $t \geq \bar{T}$ Equation (6.9), above, implies $\lambda_{t}=\lambda$ for all $t$. We do not yet solve for the constant $\lambda$. Instead we conjecture a solution in which $c_{t}^{T}=\bar{c}^{T}$ for $t \geq \bar{T}+1$. Our algorithm for solving the model begins with an outer loop in which we guess the value of $\bar{c}^{T}$.

Given our assumptions about $y_{t}^{N}$ and $g_{t}^{N}$, it follows from (6.13) that

$$
c_{t}^{N}=\bar{c}^{N} \equiv y^{N}-g^{N}-\delta \bar{c}^{T}, \text { for } t \geq \bar{T}+1 .
$$

It follows that $c_{t}=\bar{c} \equiv\left(\bar{c}^{T}\right)^{\omega}\left(\bar{c}^{N}\right)^{1-\omega}$ for $t \geq \bar{T}+1$. We conjecture that $S_{t+1} / S_{t}=1+\mu n$ for $t \geq \bar{T}+1$. Defining $N \equiv(1+\rho n)(1+\mu n)$, we then have, from (6.10),

$$
\theta_{t}=\bar{\theta}=\lambda \frac{N-1}{N}, \text { for } t \geq \bar{T}+1 \text {. }
$$

The first-order condition for $c_{t}^{T},(6.7)$, implies

$$
n \bar{c}^{1-\sigma} \omega / \bar{c}^{T}=\lambda\left(n+\frac{N-1}{N} \eta\right)\left(1+\delta \bar{p}^{N}\right) .
$$

\section{Flexible Prices}

When nontradable prices are flexible, the first-order condition for $c_{t}^{N},(6.8)$, implies $p_{t}^{N}=$ $P_{t}^{N} / S_{t}$ is a constant $\bar{p}^{N}$ for $t \geq \bar{T}+1$, where

$$
n \bar{c}^{1-\sigma}(1-\omega) / \bar{c}^{N}=\lambda\left(n+\frac{N-1}{N} \eta\right) \bar{p}^{N} .
$$

\footnotetext{
${ }^{29} \mathrm{We}$ do this for technical reasons. If we assumed otherwise, the model would be much harder to solve for $t^{*}<t \leq T$.
} 
Notice that (6.28) and (6.29) can be solved for $\lambda$ and $\bar{p}^{N}$ :

$$
\bar{p}^{N}=\frac{(1-\omega) \bar{c}^{T}}{\omega \bar{c}^{N}-\delta(1-\omega) \bar{c}^{T}}
$$

and

$$
\lambda=\frac{n N \bar{c}^{1-\sigma}(1-\omega)}{[n N+(N-1) \eta] \bar{p}^{N} \bar{c}^{N}} .
$$

\section{Sticky Prices}

When nontradable prices are sticky they do not clear the market for nontradables after the crisis. In particular, there will usually either be excess demand, in which case nontradables are rationed to households (whose first-order conditions don't hold), or there will be excess supply, in which case resources are wasted. In our examples, the relative price effects "underprice" nontradables for $t \geq \bar{T}+1$. Hence we want to look at cases where the household's first-order condition for nontradables is violated.

The cash-in-advance constraint tells us

$$
M_{\bar{T}+1}=\eta\left[\left(S_{\bar{T}+1}+\delta P_{\bar{T}+1}^{N}\right) c_{\bar{T}+1}^{T}+P_{\bar{T}+1}^{N} c_{\bar{T}+1}^{N}\right] .
$$

We know that $c_{\bar{T}+1}^{T}=\bar{c}^{T}, c_{\bar{T}+1}^{N}=\bar{c}^{N}, M_{\bar{T}+1}=M_{T}(1+\mu n)^{\bar{T}+1-T}$, and $P_{\bar{T}+1}^{N}=P_{T_{p}}^{N}=P^{N}$. In this case we can write

$$
M_{T}(1+\mu n)^{\bar{T}+1-T}=\eta\left[S_{\bar{T}+1} \bar{c}^{T}+\left(\delta \bar{c}^{T}+\bar{c}^{N}\right) P^{N}\right]
$$

or

$$
S_{\bar{T}+1}=\frac{M_{T}(1+\mu n)^{\bar{T}+1-T}-\eta\left(\delta \bar{c}^{T}+\bar{c}^{N}\right) P^{N}}{\eta \bar{c}^{T}} .
$$

Then we have $\bar{p}^{N}=P^{N} / S_{\bar{T}+1}$. From (6.28) we can solve for $\lambda$ :

$$
\lambda=\frac{n N \bar{c}^{1-\sigma} \omega / \bar{c}^{T}}{[N n+(N-1) \eta]\left(1+\delta \bar{p}^{N}\right)} .
$$

In both cases, $\bar{\theta}$ can then be determined using (6.27). It is useful to note that real balances, $M_{t} / S_{t}=\bar{m}$, a constant, for $t \geq \bar{T}+1$, where

$$
\bar{m}=\eta\left[\left(1+\delta \bar{p}^{N}\right) \bar{c}^{T}+\bar{p}^{N} \bar{c}^{N}\right]
$$

Hence, $S_{t}=M_{t} / \bar{m}$ for $t \geq \bar{T}+1$. This, of course, verifies our guess that $S_{t+1} / S_{t}=1+\mu n$ for $t \geq \bar{T}+1$, since $M_{t+1} / M_{t}=1+\mu n$ for $t \geq T$ and $T \leq \bar{T}$.

The Pre-Crisis Period: $0 \leq t<t^{*}$ We assume $S_{t}=S$ for $0 \leq t \leq t^{*}$. Given that we know $\lambda_{t}=\lambda$ for all $t$, we have

$$
\theta_{t}=\underline{\theta}=\lambda \frac{\rho n}{1+\rho n} \text { for } 0 \leq t<t^{*}
$$


Given our other assumptions, we conjecture a solution in which $c_{t}^{T}=\underline{c}^{T}, c_{t}^{N}=\underline{c}^{N}$, and $P_{t}^{N}=\underline{p}^{N} S$ for $0 \leq t<t^{*}$. The resource constraint for nontradables and the first-order conditions for $c_{t}^{T}$ and $c_{t}^{N}$ then imply:

$$
\begin{aligned}
n\left[\left(\underline{c}^{T}\right)^{\omega}\left(\underline{c}^{N}\right)^{1-\omega}\right]^{1-\sigma} \omega\left(\underline{c}^{T}\right)^{-1} & =(\lambda n+\underline{\theta} \eta)\left(1+\delta \underline{p}^{N}\right) \\
n\left[\left(\underline{c}^{T}\right)^{\omega}\left(\underline{c}^{N}\right)^{1-\omega}\right]^{1-\sigma}(1-\omega)\left(\underline{c}^{N}\right)^{-1} & =\left(\lambda n+\underline{\theta}_{\eta}\right) \underline{p}^{N} \\
\underline{c}^{N} & =y^{N}-g^{N}-\delta \underline{c}^{T} .
\end{aligned}
$$

When nontradable prices are flexible, all of these equations hold. When nontradable prices are sticky, either (6.37) or (6.38) does not hold.

\section{Flexible Prices}

We can write $\underline{c}^{N}$ as $\underline{c}^{N}\left(\underline{c}^{T}\right)$ using (6.38) and then use (6.37) to write $\underline{p}^{N}$ as $\underline{p}^{N}\left(\underline{c}^{T}\right)$. We can then solve (6.36) as a nonlinear equation in $\underline{c}^{T}$ :

$$
n\left[\left(\underline{c}^{T}\right)^{\omega} \underline{c}^{N}\left(\underline{c}^{T}\right)^{1-\omega}\right]^{1-\sigma} \omega\left(\underline{c}^{T}\right)^{-1}=(\lambda n+\underline{\theta} \eta)\left[1+\delta \underline{p}^{N}\left(\underline{c}^{T}\right)\right] .
$$

Once one has the solution for $\underline{c}^{T}$, it is straightforward to again use (6.38) and (6.37) to solve for $\underline{c}^{N}$ and $\underline{p}^{N}$.

\section{Sticky Prices}

Since we assume that $P_{t}^{N}=P^{N}$ for $t \leq T_{p}$, we have $p_{t}^{N}=p^{N}=p^{N}=P^{N} / S$ for $0 \leq t \leq t^{*}$. To solve for $\underline{c}^{T}$ and $\underline{c}^{N}$ we first assume that (6.36) and (6.37) hold and that (6.38) does not hold with equality. Solving (6.36) and (6.37) for $\underline{c}^{T}$ and $\underline{c}^{N}$ we get:

$$
\begin{gathered}
\underline{c}^{T}=\left[\frac{(\lambda n+\underline{\theta} \eta)\left(1+\delta \underline{p}^{N}\right)}{n \omega}\right]^{\frac{(\omega-1) \sigma-\omega}{\sigma}}\left[\frac{n(1-\omega)}{\left(\lambda n+\underline{\theta}_{\eta} \underline{p}^{N}\right.}\right]^{(\omega-1) \frac{\sigma-1}{\sigma}} \\
\underline{c}^{N}=\left[\frac{n\left(\underline{c}^{T}\right)^{\omega(1-\sigma)}(1-\omega)}{(\lambda n+\underline{\theta} \eta) \underline{p}^{N}}\right]^{\frac{1}{\omega+(1-\omega) \sigma}}
\end{gathered}
$$

Using these solutions we check whether $y^{N}-g^{N}-\delta \underline{c}^{T}-\underline{c}^{N} \geq 0$. If it is we stop.

If the condition we checked in the previous paragraph is violated, then we abandon the household's first order condition for $c_{t}^{N},(6.37)$, and impose the resource constraint, (6.38), instead. Combining (6.36) and (6.38) we get the following nonlinear equation for $\underline{c}^{T}$ :

$$
n \omega\left[\left(\underline{c}^{T}\right)^{\omega}\left(y^{N}-g^{N}-\delta \underline{c}^{T}\right)^{1-\omega}\right]^{1-\sigma}=(\lambda n+\underline{\theta} \eta)\left(1+\delta p^{N}\right) \underline{c}^{T} .
$$

We then use (6.38) to solve for $\underline{c}^{N}$.

For either flexible or sticky prices we use the cash-in-advance constraint to solve for

$$
M_{t}=\underline{M} \equiv \eta\left[\left(1+\delta \underline{p}^{N}\right) \underline{c}^{T}+\underline{p}^{N} \underline{c}^{N}\right] S, \text { for } t<t^{*}
$$


The Transition Period: $t^{*} \leq t \leq \bar{T}$ We have $M_{t}=\underline{M}(1-\chi)$ for $t^{*} \leq t<T$ and $M_{t}=M_{T}(1+\mu n)^{t-T}$ for $t \geq T$. We will recursively generate $S_{t}$ starting from $t^{*}$, where we have assumed $S_{t^{*}}=S$. We will then work forward, allowing us to take $S_{t}$ as given when solving for the other variables. Starting from $t=t^{*}$, we then solve for $\theta_{t}, c_{t}^{T}, c_{t}^{N}, p_{t}^{N}$, and from these determine the next value of $S_{t}$.

\section{Flexible Prices}

Under flexible prices we use the cash-in-advance constraint, (6.6), the two consumption first-order conditions, (6.7) and (6.8), and the resource constraint for nontradables, (6.13), to solve for $c_{t}^{T}, c_{t}^{N}, p_{t}^{N}$, and $\theta_{t}$. If we rearrange (6.13), (6.6), and (6.8) we have

$$
\begin{aligned}
c_{t}^{N} & =y^{N}-g^{N}-\delta c_{t}^{T} \\
p_{t}^{N} & =\frac{M_{t} / S_{t}-\eta c_{t}^{T}}{\eta\left(\delta c_{t}^{T}+c_{t}^{N}\right)} \\
\theta_{t} & =\frac{n}{\eta}\left(\frac{c_{t}^{1-\sigma}(1-\omega)}{p_{t}^{N} c_{t}^{N}}-\lambda\right),
\end{aligned}
$$

where $c_{t}=\left(c_{t}^{T}\right)^{\omega}\left(c_{t}^{N}\right)^{1-\omega}$.

For any $c_{t}^{T}$, we can think of $(6.44),(6.45)$, and (6.46) defining implicit functions $c_{t}^{N}\left(c_{t}^{T}\right)$, $p_{t}^{N}\left(c_{t}^{T}\right)$, and $\theta_{t}\left(c_{t}^{T}\right)$. Therefore, implicitly we can solve (6.7):

$$
n \omega\left\{\left(c_{t}^{T}\right)^{\omega} c_{t}^{N}\left(c_{t}^{T}\right)^{1-\omega}\right\}^{1-\sigma}=\left[\lambda n+\theta_{t}\left(c_{t}^{T}\right) \eta\right]\left[1+\delta p_{t}^{N}\left(c_{t}^{T}\right)\right] c_{t}^{T}
$$

for $c_{t}^{T}$.

\section{Sticky Prices}

When prices are sticky we will use (6.6), (6.7), and either (6.8) or (6.13) to solve for $\theta_{t}$, $c_{t}^{T}$, and $c_{t}^{N}$. Assuming that (6.13) is the equation that does not hold with equality, we can solve for $\theta_{t}, c_{t}^{T}$, and $c_{t}^{N}$ as follows. Implicitly (6.6) defines $c_{t}^{N}$ in terms of $c_{t}^{T}$ :

$$
c_{t}^{N}=\frac{M_{t}-\eta\left(S_{t}+\delta P^{N}\right) c_{t}^{T}}{\eta P^{N}} .
$$

We can then use (6.8) to obtain $\theta_{t}$ in terms of this solution for $c_{t}^{N}$ and the value of $c_{t}^{T}$ :

$$
\theta_{t}=\frac{n}{\eta}\left\{\left[\left(c_{t}^{T}\right)^{\omega}\left(c_{t}^{N}\right)^{1-\omega}\right]^{1-\sigma}(1-\omega)\left(c_{t}^{N}\right)^{-1} \frac{S_{t}}{P^{N}}-\lambda\right\}
$$

Then we can solve the remaining equation, (6.7), for $c_{t}^{T}$, using the same method described above for the flexible price case.

If at any point (6.13) is violated, in that $c_{t}^{N}$ is too large, we must let the first-order condition for $c_{t}^{N}$ be violated. In this case we solve (6.6), (6.7), and (6.13) for $\theta_{t}, c_{t}^{T}$, and $c_{t}^{N}$. Notice that (6.6) and (6.13), are linear in $c_{t}^{T}$ and $c_{t}^{N}$, and do not involve $\theta_{t}$. Hence, we can solve

$$
\left(\begin{array}{ll}
\eta\left(S_{t}+\delta P^{N}\right) & \eta P^{N} \\
\delta & 1
\end{array}\right)\left(\begin{array}{l}
c_{t}^{T} \\
c_{t}^{N}
\end{array}\right)=\left(\begin{array}{l}
M_{t} \\
y^{N}-g^{N}
\end{array}\right)
$$


or

$$
\left(\begin{array}{l}
c_{t}^{T} \\
c_{t}^{N}
\end{array}\right)=\left[\begin{array}{l}
M_{t}-\eta P^{N}\left(y^{N}-g^{N}\right) \\
\eta\left(S_{t}+\delta P^{N}\right)\left(y^{N}-g^{N}\right)-\delta M_{t}
\end{array}\right] /\left(\eta S_{t}\right) .
$$

We then solve for $\theta_{t}$ using (6.7):

$$
\theta_{t}=\frac{n\left[\left(c_{t}^{T}\right)^{\omega}\left(c_{t}^{N}\right)^{1-\omega}\right]^{1-\sigma} \omega\left(c_{t}^{T}\right)^{-1}-\lambda n\left(1+\delta P^{N} / S_{t}\right)}{\eta\left(1+\delta P^{N} / S_{t}\right)}
$$

Regardless of whether prices are sticky or flexible, once we have $\theta_{t}, c_{t}^{T}, c_{t}^{N}$, and $p_{t}^{N}$, we can generate $S_{t+1}$ using

$$
S_{t+1}=\frac{\lambda}{\lambda-\theta_{t}} \frac{S_{t}}{1+\rho n}
$$

Iterating on $\chi$ When we are done generating the data for the transition period we will have a sequence $\left\{S_{t}\right\}$ for $t^{*}<t<\bar{T}+1$. Notice that the $S_{\bar{T}+1}$ generated this way may not match the $S_{\bar{T}+1}$ we generated in the section on the post-crisis steady state. If it does not match, then the value of $\chi$ must be changed. If the "transition period" value of $S_{\bar{T}+1}$ is greater than the "steady-state" value of $S_{\bar{T}+1}$, then we make $\chi$ smaller.

Iterating on $\bar{c}^{T}$ The lifetime budget constraint of the household, (6.5), must be satisfied. We have assumed that

$$
\sum_{t=0}^{\infty}(1+n r)^{-(t+1)} n \tilde{v}_{t}=\frac{\tilde{v}}{r}+\tilde{\phi} .
$$

We can rewrite the lifetime budget constraint as

$$
\begin{gathered}
a_{-1}+\tilde{\phi}+\frac{\tilde{v}}{r}+\sum_{t=0}^{\infty}(1+n r)^{-(t+1)} n\left[y^{T}-\left(1+\delta p_{t}^{N}\right) c_{t}^{T}+p_{t}^{N}\left(y^{N}-c_{t}^{N}\right)-\tau_{t}+\hat{v} \frac{P_{t}}{S_{t}}+\frac{r B}{S_{t}}\right] . \\
=\sum_{t=0}^{\infty}(1+n r)^{-(t+1)} \frac{M_{t}-M_{t-1}}{S_{t}}
\end{gathered}
$$

The right hand side of (6.48), which I will denote by $R H S$, is seigniorage. Notice that

$$
\begin{gathered}
R H S=(1+n r)^{-1} \frac{\frac{M}{2}-M}{S}-(1+n r)^{-\left(t^{*}+1\right)} \frac{M \chi}{S}+(1+n r)^{-(T+1)} \frac{M_{T}-\underline{M}(1-\chi)}{S_{T}}+ \\
\sum_{t=T+1}^{\bar{T}}(1+n r)^{-(t+1)} \frac{M_{t}-M_{t-1}}{S_{t}}+(1+n r)^{-(\bar{T}+1)} \frac{\mu \bar{m}}{(1+\mu n) r} .
\end{gathered}
$$

We can compute the relevant pieces of the left-hand side as follows. Define $L H S_{1} \equiv \sum_{t=0}^{\infty}(1+$ $n r)^{-(t+1)} Z_{1 t}$, where

$$
Z_{1 t}=n\left[y^{T}-\left(1+\delta p_{t}^{N}\right) c_{t}^{T}+p_{t}^{N}\left(y^{N}-c_{t}^{N}\right)-\left(\tau^{T} y^{T}+\tau^{N} y^{N} p_{t}^{N}+\tau^{L}\right)\right] .
$$


Since

$$
\begin{aligned}
& Z_{1 t}= \begin{cases}\underline{Z}_{1} \quad \text { for } 0 \leq t<t^{*} \\
\bar{Z}_{1} \text { for } t \geq \bar{T}+1 .\end{cases} \\
& \underline{Z}_{1}=n\left\{\left(1-\tau^{T}\right) y^{T}-\left(1+\delta \underline{p}^{N}\right) \underline{c}^{T}+\underline{p}^{N}\left[\left(1-\tau^{N}\right) y^{N}-\underline{c}^{N}\right]-\tau^{L}\right\} \\
& \bar{Z}_{1}=n\left\{\left(1-\tau^{T}\right) y^{T}-\left(1+\delta \bar{p}^{N}\right) \bar{c}^{T}+\bar{p}^{N}\left[\left(1-\tau^{N}\right) y^{N}-\bar{c}^{N}\right]-\tau^{L}\right\},
\end{aligned}
$$

we have

$$
L H S_{1}=\left[1-(1+n r)^{-t^{*}}\right] \frac{\underline{Z}_{1}}{n r}+\sum_{t=t^{*}}^{\bar{T}}(1+n r)^{-(t+1)} Z_{1 t}+\frac{(1+n r)^{-(\bar{T}+1)}}{n r} \bar{Z}_{1} .
$$

We also have $L H S_{2} \equiv \sum_{t=0}^{\infty}(1+n r)^{-(t+1)} n r B / S_{t}$ so that

$$
L H S_{2}=\frac{B}{S}\left[1-(1+n r)^{-\left(t^{*}+1\right)}\right]+n r B \sum_{t=t^{*}+1}^{\bar{T}}(1+n r)^{-(t+1)} / S_{t}+n r B \frac{(1+n r)^{-(\bar{T}+1)}}{(N-1) M_{\bar{T}} / \bar{m}} .
$$

We have $L H S_{3} \equiv \sum_{t=0}^{\infty}(1+n r)^{-(t+1)} n \hat{v} P_{t} / S_{t}$ so that

$$
L H S_{3}=\left[1-(1+n r)^{-t^{*}}\right] \frac{\hat{v} \underline{P} / S}{r}+n \sum_{t=t^{*}}^{\bar{T}}(1+n r)^{-(t+1)} \hat{v} \frac{P_{t}}{S_{t}}+\frac{(1+n r)^{-(\bar{T}+1)}}{r} \hat{v} \frac{P_{\bar{T}+1}}{S_{\bar{T}+1}}
$$

If we find that the household's lifetime budget constraint in not satisfied, we change our guess for $\bar{c}^{T}$.

Iterating on $\mu$ Here we must evaluate the government's lifetime budget constraint, given by (6.25). Notice that (6.25) can be rewritten as

$$
\phi+L H S_{1}^{G}+L H S_{2}^{G}+L H S_{2}+L H S_{3}-\frac{1}{r}\left(p^{N} g^{N}-\tau^{N} y^{N} p^{N}+\hat{v} \frac{P}{S}+\frac{r B}{S}\right)=R H S
$$

where $L H S_{1}^{G} \equiv \sum_{t=0}^{\infty}(1+n r)^{-(t+1)} n p_{t}^{N} g^{N}$ and $L H S_{2}^{G} \equiv-\sum_{t=0}^{\infty}(1+n r)^{-(t+1)} n \tau^{N} y^{N} p_{t}^{N}$. We can show that $L H S_{1}^{G}=\Gamma g^{N}$ and $L H S_{2}^{G}=-\Gamma \tau^{N} y^{N}$ where

$$
\Gamma=\left[1-(1+n r)^{-t^{*}}\right] \frac{\underline{p}^{N}}{r}+\sum_{t=t^{*}}^{\bar{T}}(1+n r)^{-(t+1)} n p_{t}^{N}+(1+n r)^{-(\bar{T}+1)} \frac{\bar{p}^{N}}{r} .
$$

If the government's lifetime budget constraint is not satisfied, we adjust our guess for $\mu$. 